\title{
ANÁLISE CRÍTICA DE GÊNEROS: CONTRIBUIÇÕES PARA O ENSINO E A PESQUISA DE LINGUAGEM ${ }^{1}$
}

\author{
(Critical genre analysis: contributions to language \\ teaching and research)
}

\author{
Désirée MotTA-RotH \\ (LABLER-Laboratório de Pesquisa e Ensino de Leitura e Redação \\ Universidade Federal de Santa Maria)
}

\begin{abstract}
Resumo: É crescente o interesse pela análise de práticas discursivas em contextos específicos, envolvendo atividades e papéis sociais recorrentes. $O$ conceito de gênero discursivo tem emergido como um uma ferramenta de teorização e de explanação sobre como a linguagem funciona para criar e recontextualizar interações sociais. $O$ objetivo do presente artigo é apresentar um levantamento amplo da discussão sobre o conceito de gênero na literatura recente, especialmente em relação à delimitação, análise e interpretação da linguagem como gênero sob uma perspectiva crítica. Contribuições para as práticas pedagógicas de linguagem são apontadas, tomando por referência a Análise de Gêneros, a Análise do Discurso Crítica, a Lingüística Sistêmico-Funcional e o Interacionismo Sócio-Discursivo. Palavras-Chave: Análise Crítica de Gêneros, levantamento de pesquisa, linguagem e atividade, implicações para o ensino e aprendizagem de línguas
\end{abstract}

AвSTRACT: There is an increasing interest on the analysis of discursive practices in specific contexts, involving recurrent social activities and roles. The concept of discursive genre has emerged as a tool for theorizing and explaining on how language functions in order to create and to re-contextualize social interactions. The objective of the present article is to present an overview of the research work around the concept of genre in recent literature, especially relating to the delimitation, analysis and interpretation of language

1. Trabalho desenvolvido com apoio CNPq (Bolsa PQ/2005-2008, nº 304256/2004-8), apresentado como conferência plenária, intitulada "Contribuições da análise crítica de gêneros discursivos para a pesquisa e o ensino da linguagem" no IV SIGET - Simpósio Internacional de Estudos de Gêneros Textuais, realizado na UNISUL, em Tubarão, SC, em 16/08/2007. Agradeço ao parecerista pelas orientações para a edição do trabalho e a Eliseu Alves da Silva e Fabio Santiago Nascimento (PIBIC/UFSM), pelas sugestões e revisão do texto. Os problemas que perduram são de minha responsabilidade.

D.E.L.T.A., 24:2, 2008 (341-383) 
as genre under a critical perspective. Contributions to the language pedagogy are pointed out with reference to Genre Analysis, Critical Discourse Analysis, Systemic-Functional Linguistics, and Socio-Discursive Interactionism.

KEY-WORDS: Critical Genre Analysis, overview of research work, language and activity, implications for language teaching and learning

\section{Introdução}

Há, na atualidade, um crescente interesse pela análise de diferentes gêneros discursivos da vida social a partir de atividades e papéis sociais recorrentes do dia a dia em uma diversidade de contextos culturais (ver, por exemplo, Kaufer 2006; Al-Ali 2006; Jorge \& Heberle 2002; Machado e Cristóvão 2006). Em virtude desse interesse, busco fazer, neste trabalho, um inventário de contribuições teórico-metodológicas da Análise Crítica de Gêneros para a pesquisa e o ensino da linguagem. Para tanto, localizo historicamente os estudos de gêneros discursivos, sintetizo a discussão sobre o conceito na literatura e, por fim, aponto algumas contribuições da perspectiva crítica sobre os gêneros para a pesquisa e o ensino da linguagem.

\section{Breve histórico}

Este apanhado histórico é apenas uma versão unilateral e limitada dos estudos de gêneros discursivos no Brasil e no exterior. Delimito meu lugar de fala para traçar esse histórico como membro GT do Grupo de Trabalho de Lingüística Aplicada da ANPOLL-Associação Nacional de Pesquisa e Pós-Graduação em Letras e Lingüística, atuando no Sub-GT de "Teorias de Gêneros em Práticas Sociais”. É desse lugar bem restrito que escrevo: como analista do texto e do discurso, formadora de professores de linguagem, interessada no ensino de leitura e redação e na metodologia de pesquisa que usamos para analisar os gêneros discursivos (Motta-Roth 2006a; 2006b). O GT de LA combina pessoas interessadas nesses 3 pontos focais: Teoria e Análise de Gêneros no Contexto Social, Formação de Professores e Ensino e Aprendizagem.

Inicio minha exposição, partindo desse lugar para fazer uma pequena "cartografia" da pesquisa no âmbito internacional, comparando-as e inventariando algumas de suas contribuições teórico-metodológicas. Em se- 
guida, localizo os estudos sobre gêneros no Brasil em relação à história recente do Sub-GT de “Teorias de Gêneros em Práticas Sociais”. Por fim, sintetizo algumas contribuições teórico-metodológicas da análise crítica de gêneros discursivos para a pesquisa e o ensino da linguagem.

\subsection{Breve histórico no âmbito internacional}

Embora tenha sido explorado desde a antiguidade, com a Retórica de Aristóteles, e por diferentes autores como Mikhail Bakhtin (1952-1953/ 1992a; b), em Os gêneros do discurso e O problema do texto, o conceito de gênero certamente assumiu um novo papel na Lingüística Aplicada na década de 80, especialmente no contexto anglofônico. A partir do início da década, autores comprometidos com a educação lingüística começaram a usar o termo com freqüência na teorização das práticas. Exemplos de marcos teóricos são: o trabalho sobre introduções de artigos de John Swales (1981), o artigo de Carolyn Miller (1984) acerca dos gêneros como tipos de ação social, o livro de Gunther Kress (1989) sobre gêneros como processos lingüísticos na prática sociocultural e o de Jim Martin (1985/1989) sobre o ensino de redação na escola como uma prática concreta de exploração e desafio da realidade social.

Esses autores se deslocam na história, mudando seu foco de interesse em termos do aspecto da linguagem que enfatizam (elementos léxico-gramaticais, estruturas retóricas, contextualização do discurso) ou alterando sua visada teórica sobre o mesmo objeto de estudo, transformando, assim, a sua própria representação do conceito de gênero. Apesar das diferenças, esses autores guardam um ponto comum: a análise de textos, em seu conteúdo temático, organização retórica e formas lingüísticas, em função dos objetivos comunicativos compartilhados por pessoas envolvidas em atividades sociais, em contextos culturais específicos.

Ao descrever esses deslocamentos na história da pesquisa sobre gêneros no contexto anglofônico, Bhatia (2004: 3-12) identifica três fases cronológicas nos estudos do texto escrito, as quais encontram correspondência com boa parte dos estudos dos gêneros textuais no Brasil.

A primeira fase identificada por Bhatia (2004: 4-8) inclui os estudos das décadas de 60, 70 e virada dos anos 80 , que buscavam verificar a recor- 
rência de elementos léxico-gramaticais dentro dos limites da sentença. Os estudos dessa primeira fase enfocavam a textualização e a léxico-gramática. Já na parte final dessa fase, as pesquisas identificam-se com a Lingüística Textual de autores como Beaugrande \& Dressler (1981), pois buscavam identificar traços de textualidade na superfície dos textos.

Nos anos 80 e 90, os estudos sobre organização textual da segunda fase (cf.: Bhatia 2004: 8-10) enfocavam a macroestrutura do texto para identificar regularidades na organização do discurso em termos de estruturas textuais básicas, estruturas retóricas ou esquemáticas. A ênfase é menos no contexto e mais nos aspectos macroestruturais.

Ao final dos anos 90 e início dos 2000, surgem múltiplos olhares sobre o fenômeno dos gêneros discursivos, com freqüente referência aos escritos de Mikhail Bakhtin e à análise do discurso crítica de Norman Fairclough. Essa terceira fase dos estudos de gêneros escritos enfatiza a contextualização do discurso, os aspectos externos da construção dos gêneros (cf.: Bhatia 2004: 11).

Cada uma dessas épocas representa um marco no desenvolvimento da teorização sobre gêneros, especialmente na segunda e na terceira fases.

A segunda fase representa um marco, porque, nessa época, emergem as teorias de gênero sobre textos escritos institucionalizados, especialmente aqueles do contexto educacional (cf.: Bhatia 2004:10). Nessa fase, criase um aparato teórico com três enquadramentos teóricos (cf.: Hyon 1996; Bhatia 2004), freqüentemente chamados de escolas:

1. A escola britânica de ESP, formada por autores como Swales (1990) e Bhatia (1993), com foco na organização retórica dos "tipos de textos, definidos por suas propriedades formais bem como por seus objetivos comunicativos dentro de contextos sociais" (Hyon 1996: 695);

2. A Escola Americana da nova retórica ou sócio-retórica, representada por Bazerman (1988) e Miller (1984), com foco nos contextos sociais e nos atos de fala que os gêneros realizam numa dada situação (Hyon 1996:696);

3. A Escola Sistêmico-Funcional de Sydney, representada por Halliday e Hasan (1985/1989) e Martin (1985/1989), com foco na léxico-gramática e nas funções desempenhadas por ela nos contextos sociais. 
Por sua importância atual no cenário brasileiro, devemos acrescentar, a essa descrição, uma quarta tendência, a da chamada escola suíça, representada por autores como Jean-Paul Bronckart, Bernard Schneuwly e Joachin Dolz. Tomando o trabalho de J.-P. Bronckart como exemplo, pode-se dizer que o Interacionismo Sócio-Discursivo (ISD) teoriza centralmente sobre a semiotização das relações sociais, tendo como base o trabalho do Círculo de estudos de Lev Vygotsky (Bronckart 1999:13; Bronckart 2006:7; 9-10; 15) e o conceito de ação social, desenvolvido nas teses de Gertrude Elizabeth Margareth Anscombe (1957) e Jürgen Habermas (1987) (cf.: Bronckart 2006:15; 46).

O ISD contesta a atual divisão das Ciências Humans/Sociais por não se inscrever apenas numa ou noutra área, se constituindo em "uma corrente da ciência do humano" e postulando que o "problema da linguagem é absolutamente central ou decisivo para essa ciência do humano (Bronckart 2006:10). Nesses termos, o quadro do ISD leva á análise da ação da linguagem como ação imputada a um agente, por um motivo e com uma intenção, situada em formações sociais identificáveis (Bronckart 1999:13). A ação de linguagem é analisada por meio do texto, a partir de tipos de discurso (teórico, interativo, etc.) e seqüências (narrativa, argumentativa, etc), mecanismos de textualização (conectores, coesão nominal, etc.) e mecanismos enunciativos (modalização, voz, etc.) (Bronckart 1999: 113-35).

As pesquisas desenvolvidas no Brasil na década de 90 identificam-se em grande escala com essas quatro escolas e originam um pensamento voltado para as práticas pedagógicas de linguagem. Constrói-se no país um arcabouço teórico fundado nessas quatro escolas que vai servir de base para propostas diversas como as de políticas públicas como os PCN (cf.: Brasil 1997), que tem influência do ISD e da teorização de Mikhail Bakhtin (por exemplo, 1952-1953/1992a; b), ou as de reformas curriculares, como a recentemente implementada no Curso de Letras-Inglês da UFSM (cf.: Brasil 2004), inspirada nos quadros teóricos da sociorretórica americana e da lingüística sistêmico-funcional australiana.

Antes de aprofundar a discussão sobre o conceito de gênero nessas quatro tendências, faço um inventário da pesquisa no Brasil a partir da perspectiva unilateral delimitada por mim. 


\subsection{Breve bistórico no âmbito local}

No Brasil, em 1992, havia um grupo de pesquisa na Universidade Federal de Santa Catarina (UFSC) que gravitava ao redor de dois professores da UFSC: José Luiz Meurer e Carmen Rosa Caldas Coulthard (e, em alguma medida, em torno de Malcom Coulthard). Naquela época, J. L. Meurer implementou um programa de estudos sobre gêneros com seus alunos de mestrado e doutorado. Um pouco depois, colegas atuantes em diferentes instituições brasileiras foram saindo para suas licenças sabáticas e se espalharam teórica e geograficamente pelo mundo. Muitas dessas pessoas hoje fazem parte do Sub-GT “Teorias de Gêneros em Práticas Sociais” da ANPOLL e, para fazer uma retrospectiva, olhei a minha história de pesquisa e ensino sobre gêneros e também a dessas pessoas.

Ao olhar os currículos Lattes dos 24 membros do Sub-GT de Gêneros em Práticas Sociais da ANPOLL ${ }^{2}$ é possível fazer um levantamento de artigos, livros e trabalhos completos em anais, publicados no Brasil, ao longo dos anos até década de 90, com a palavra "gênero" em seu título. A partir de 1995, surge no Brasil uma onda de trabalhos voltados ao ensino e à pesquisa da língua escrita com base em gêneros, especialmente na UFSCUniversidade Federal de Santa Catarina (Motta-Roth 1995; Bonini 1998), na UFSM-Universidade Federal de Santa Maria (Motta-Roth \& Hendges 1996), na PUC de São Paulo (Rojo 1997; Machado 1998) e na UECE-Universidade Estadual do Ceará (Araújo 1998). Esses estudos se baseavam em enquadramentos teóricos diferentes, conforme mencionarei mais adiante.

Durante a década de 90, colegas do Sub-GT de Gêneros da ANPOLL desenvolveram inúmeras pesquisas para tentar mapear gêneros tão diversos quanto o gênero editorial de revistas femininas (Heberle 1995), apresentações acadêmicas (Balocco \& Dantas 1997), textos de auto-ajuda (Meurer 1998), sentenças jurídicas em casos de estupro (Figueiredo 1998), bate-papo virtual (Braga 1999), resumos de dissertações (Biasi-Rodrigues 1999) e gêneros empresarias (Barbara (com Scott, 1999).

O conceito de gênero se integrou ao conhecimento normalizado da disciplina, com um indicador muito significativo de sua relevância no Bra-

2. Para ver nomes de todos os Membros do GT de Lingüística Aplicada da ANPOLL consultar: http://coralx.ufsm.br/desireemroth/gtlaanpoll/index.htm. 
sil: o papel central da idéia de gêneros nos Parâmetros Curriculares Nacionais (Brasil 1997), de cuja elaboração muitos dos colegas fizeram parte. A construção dos Parâmetros Curriculares Nacionais (PCN) foi concebida como um processo contínuo de invenção: eles deveriam influenciar positivamente a prática do professor e, ao mesmo tempo, deveriam poder, com base nessa prática e no processo de aprendizagem dos alunos, ser revistos e aperfeiçoados (cf.: Brasil 2000:4).

Originalmente o objetivo dos PCN foi "dar significado ao conhecimento escolar, mediante a contextualização; evitar a compartimentalização, mediante a interdisciplinaridade; e incentivar o raciocínio e a capacidade de aprender... [para] difundir os princípios da reforma curricular e orientar o professor, na busca de novas abordagens e metodologias." (Brasil 2000:4).

Apesar das controvérsias surgidas entre pesquisadores brasileiros sobre sua adequação ou mesmo legitimidade, para muitos deles, os PCN "se constituem como o guia maior das diferentes atividades educacionais no Brasil" (Bronckart \& Machado 2004: 140). Ao defender o conceito de gênero como base da elaboração da proposta pedagógica de ensino de linguagem (Línguas Portuguesa e Estrangeira), o documento, faz uma contribuição importante no que tange à pesquisa e à prática pedagógica em linguagem:

A perspectiva da linguagem adotada nos Parâmetros Curriculares Nacionais (doravante $\mathrm{PCN}$ ) é orientada para a vida social e se configura em um avanço, se comparada à visão estruturalista amplamente adotada na escola até bem recentemente, em que se definia um programa de curso em termos de categorias da gramática normativa a serem trabalhadas de modo descontextualizado, tais como a concordância verbal e o emprego dos advérbios (Motta-Roth, 2006a: 497).

Os PCN adotam uma perspectiva social da linguagem ao defender uma aprendizagem que vai "além da memorização mecânica de regras gramaticais ou das características de determinado movimento literário, o aluno deve ter meios para ampliar e articular conhecimentos e competências que possam ser mobilizadas nas inúmeras situações de uso da língua com que se depara, na família, entre amigos, na escola, no mundo do trabalho" (cf.: Brasil 2002:55)

Na primeira metade da década de 2000, os membros do Sub-GT de Gêneros em Práticas Sociais da ANPOLL produziram muitos estudos de 
gênero em núcleos de pesquisa espalhados por quatro das cinco regiões do Brasil: ${ }^{3}$

- Região Sul - Motta-Roth (com Hendges et al., 2000) na UFSM; Guimarães (2005) na UNISINOS; Baltar (2004) na UCS-Universidade de Caxias do Sul; Meurer (2000) na UFSC; Nascimento (com Cristóvão, 2005) na UEL-Universidade Estadual de Londrina;

- Região Sudeste - Vian Jr (2003) e Machado (com A. P. Dionísio e M. A. Bezerra, 2002) na PUC-São Paulo; Balocco (2001) e Carvalho (2000) na UERJ-Universidade do Estado do Rio de Janeiro; Silva (2004) na Universidade Federal de Juiz de Fora;

- Região Nordeste - Biasi-Rodrigues (2001) na UFCE-Universidade Federal do Ceará; Araújo (2004) na UECE; e

- Região Centro-Oeste - Padilha (com Barros-Mendes, 2005) na UFMT-Universidade Federal do Mato Grosso.

Ao longo da década de 2000, esses núcleos de pesquisa têm demonstrado vitalidade e produzido pesquisa sobre uma gama variada de gêneros discursivos, tanto da vida diária - como, por exemplo, o estudo de Jorge \& Heberle (2002) sobre folder bancário e de Rodrigues (2001; 2003) sobre artigos jornalísticos - quanto da vida acadêmica - como os de Machado (com Lousada e Abreu-Tardelli 2004a; 2004b) e Motta-Roth (2001) sobre abstracts, artigos, resenhas e resumos.

Em 2003, o I Simpósio Nacional de Gêneros Textuais foi proposto como um evento de caráter interdisciplinar que reunisse várias perspectivas sobre o binômio língua-cultura. O Programa de Pós-Graduação em Estudos da Linguagem da Universidade Estadual de Londrina - PR, sob a coordenação das professoras Adja Durão, Elvira Nascimento e Vera Cristóvão, realizou o $1^{\circ}$ SIGET com especialistas de Língua Materna e Estrangeira de todas as regiões do país e do exterior. O II SIGET (realizado pela Faculdade Estadual de Filosofia, Ciências e Letras, em União da Vitória, Paraná) constituiu-se em marco nas discussões e proposições de novos parâ-

3. À época deste levantamento, o sub-GT de gêneros da ANPOLL não contava com estudos sobre gêneros, desenvolvidos nas Universidades Federais da região Norte do Brasil, como, por exemplo, na do Pará, Acre ou Amapá. 
metros para as práticas de ensino de línguas e as pesquisas sobre práticas discursivas. A partir de sua terceira edição (realizado pela Universidade Federal de Santa Maria, RS) em 2005, o evento internacionalizou-se, consolidando os diálogos em torno dos gêneros discursivos entre os colegas brasileiros e estrangeiros. Isso se demonstrou mais enfaticamente na variedade regional e na internacionalização das sessões, mesas-redondas e plenárias do IV SIGET (realizado na UNISUL, SC) em 2007.

Recentemente, em 2006, a publicação das Orientações Curriculares $\mathrm{Na}$ cionais para o Ensino Médio pelo Ministério da Educação (Brasil, 2006) veio reafirmar, no âmbito brasileiro, o papel do conceito de gênero como recurso pedagógico para o ensino de como a linguagem funciona:

a ênfase... dada ao trabalho com as múltiplas linguagens e com os gêneros discursivos merece ser compreendida como uma tentativa de não fragmentar, no processo de formação do aluno, as diferentes dimensões implicadas na produção de sentidos. (Brasil, 2006:28)

o objeto de ensino privilegiado são os processos de produção de sentido para os textos, como materialidade de gêneros discursivos, à luz das diferentes dimensões pelas quais eles se constituem. (Brasil, 2006:36).

N’As Orientações Curriculares Nacionais para o Ensino Médio (OCN), os gêneros são a um só tempo recurso pedagógico e objeto de ensino.

Essa normalização do conhecimento por meio de documentos oficiais sinaliza a existência de uma dinâmica de pesquisa e ensino em torno do conceito de gênero e que segue em direção à maturação do debate na área. Como tentarei demonstrar mais adiante, essa dinâmica criou um rico aparato teórico interdisciplinar que convida ao debate sobre práticas discursivas a partir do conceito de gênero.

Nesta seção, citei apenas algumas das referências na pesquisa de gêneros escritos no país, deixando de lado vários outros autores, que também contribuíram para a área e que caberiam como citação pertinente neste trabalho. Exemplos de tantos outros trabalhos relevantes deixados de fora desse inventário são aqueles que enfocam os gêneros orais como o de Oliveira, Oliveira \& Pereira (2005) ou de Ikeda (com Dottori Filho 2006). No entanto, em função do espaço, continuarei restrita a dar apenas uma versão unilateral e limitada da história dos estudos de gênero. Embora 
diferentes em vários aspectos, as quatro ${ }^{4}$ escolas identificadas acima guardam pontos em comum em relação ao conceito de gênero, conforme passo a discutir.

\section{Definições para o conceito de gênero}

A opinião de autores das quatro escolas sobre o que é gênero parece coincidir em pelo menos dois pontos:

1. Gêneros são usos da linguagem associados a atividades sociais;

2. Essas ações discursivas são recorrentes e, por isso, têm algum grau de estabilidade na forma, no conteúdo e no estilo.

Esses princípios comuns podem ser abstraídos de definições desses autores para gênero:

1. Evento comunicativo, na Análise de Gênero de perspectiva instrumental ${ }^{5}$ praticada por Swales (1998:20) e Bhatia (2004: 54);

2. Ações retóricas típicas, na Sócio-Retórica: de Miller (1984: 151);

3. Funções semióticas específicas à cultura, na Lingüística SistêmicoFuncional de Halliday (1978: 145); e Conformação, recorrente e progressiva, de significados para realizar práticas sociais em Martin (2002);

4. Textos com características relativamente estáveis, no Interacionismo Sócio-Discursivo de Bronckart (1999: 137).

4. Meu parecerista aconselha a identificação de um quinto direcionamento dos estudos sobre gêneros realizados no Brasil, conforme desenvolvido por Rojo (Brait \& Rojo, 2001), membro do Sub-GT de Teorias de Gêneros em Práticas Sociais da ANPOLL. Tais estudos estariam associados à teoria da enunciação de M. Bakhtin e, portanto, não poderiam ser incluídos na mesma esteira de J.P. Bronckart, que associa princípios de L.S. Vygotsky, J. Habermas, e o próprio M. Bakhtin ao elaborar uma perspectiva da psicologia da educação. No entanto, como Rojo é um dos nomes centrais no processo de divulgação do trabalho de J.-P Bronckart no Brasil e como muitas das publicações dessa autora brasileira traz a palavra "gênero" no título e alude a questões pertinentes ao ISD, entendo que sua pesquisa está representada dentro da corrente do ISD, conforme descrita neste trabalho. Além disso, a perspectiva enunciativa de (e a partir de) M. Bakhtin tem centralidade em todas as quatro perspectivas mencionadas aqui.

5. Embora entenda que todas as escolas façam análise de gênero de uma maneira ou outra, adoto o termo 'Análise de Gênero' para me referir apenas a trabalhos como os de J. M. Swales e V. Bhatia, em função do livro "Análise de Gênero", publicado pelo primeiro, em 1990, ter popularizado o termo com o sentido da abordagem instrumental que hoje prevalece. 
Podemos dizer, então, que gêneros se referem a tipos relativamente estáveis de enunciados (cf.: Bakhtin, 1952-1953/1992 a; b), usados para fins específicos em um dado grupo social. São processos sociais que levam a convenções e expectativas reconhecíveis e compartilhadas (cf.: Grabe 2002: 250).

As quatro escolas de gênero, mencionadas anteriormente, estão muito presentes no contexto brasileiro atual, conforme demonstra a coletânea Teorias, métodos e debates (Meurer, Bonini e Motta-Roth 2005). Nesse volume, um grupo de autores brasileiros explica e dá exemplos da análise proposta por cada um desses enquadramentos teóricos de modo a contribuir para o entendimento das várias dimensões implicadas na produção de sentido.

Nos anos 2000, portanto, temos um cenário de múltiplos olhares sobre o fenômeno dos gêneros discursivos. Nesta última fase dos estudos do texto escrito, identificada por Bhatia (2004) como de contextualização do discurso, a referência aos escritos de Bakhtin e à análise do discurso crítica, como a proposta por Norman Fairclough, entre outros, é cada vez mais freqüente e o conceito de gênero é cada vez mais expandido para além dos limites do léxico e da gramática, para abarcar o contexto social, o discurso e a ideologia (cf.: Berkenkotter 2001; Giannoni 2002).

Tal expansão demanda que as análises considerem as condições de produção, distribuição e consumo do texto, e focalizem os textos que circulam na sociedade contra o pano de fundo do momento histórico. Olham-se as finalidades e a organização econômica dos grupos sociais, em termos de vida cotidiana, negócios, meios de produção, formações ideológicas, etc., que determinam o conteúdo, o estilo e a construção composicional dos gêneros, conforme os exemplos mostrados mais adiante de artigos acadêmicos que relatam pesquisas sobre gêneros.

Nessa fase de preocupação com o contexto social, autores de diferentes vertentes têm se concentrado em pelo menos três pontos distintos:

$\left.1^{\circ}\right) \mathrm{O}$ contexto institucional e as variações de epistemologias e práticas discursivas em diferentes áreas como o livro mais recente de Swales (2004) sobre os gêneros de pesquisa em diversas áreas e o artigo de Araújo (2005) sobre práticas discursivas em artigos de Lingüística Aplicada;

$2^{\circ}$ ) Os aspectos sócio-cognitivos e a função social dos gêneros, como o livro de Bazerman (2005) sobre gêneros textuais, tipificação e interação ou 
o estudo de Bonini (2002) sobre estruturas cognitivas de jornalistas sobre de gêneros; e

$3^{\circ}$ ) As formas de controle social exercidas pelo discurso em diferentes gêneros, como o enfoque dado aos gêneros no livro de Fairclough (2003), ou nos textos de Furlanetto (2004) e Meurer (2006).

O conceito de gênero se estabelece entre nós como uma ferramenta de teorização e de explanação (cf.: Bunzen 2006:153) sobre como a linguagem funciona associada a objetivos e atividades para criar e recontextualizar interações sociais.

Ao longo dos anos, vemos a idéia de gênero discursivo ou textual se modificar em termos do modo como a vemos e empregamos. Ampliam-se as possibilidades de análise ao longo do contínuo entre o extremo da ins-

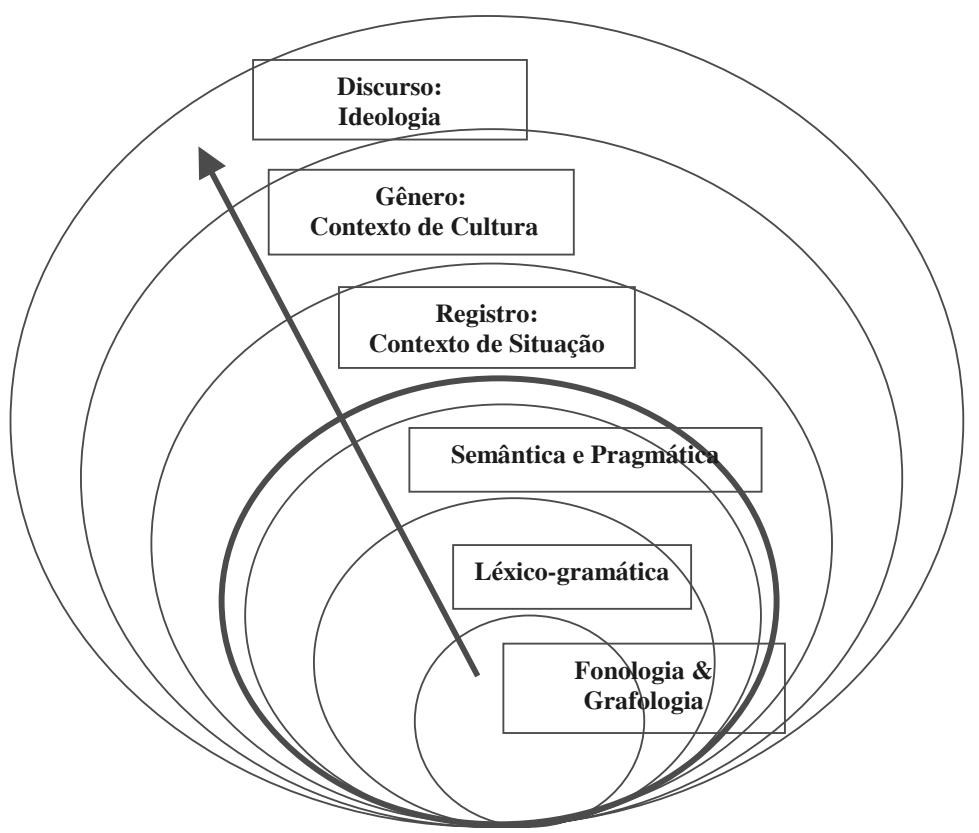

Figura 1: Desenvolvimento cronológico dos estudos de gênero em relação à estratificação dos planos comunicativos (lingüístico e contextual) (conforme adaptação de Martin (1992: 496) e de Hendges (2005: 06)). 
tância imediata de uso da linguagem - do léxico e da gramática instanciados na fonologia/grafologia - até o extremo mais abstrato - do discurso, instanciado no gênero e no registro.

Ao adaptar um modelo antigamente adotado na Lingüística Sistêmico-Funcional ${ }^{6}$, tento representar o deslocamento cronológico e o direcionamento dos estudos, ao longo do tempo, a partir dos elementos da linguagem dentro da sentença em direção aos elementos do contexto, das atividades, dos papéis e relações, das formações discursivas e ideológicas da sociedade.

A Figura 1 se presta a uma analogia visual ao desenvolvimento cronológico dos estudos de gêneros discursivos em relação à estratificação dos planos comunicativos. A flecha ascendente indica o percurso dos estudos de gêneros a partir do enfoque na instanciação fonológica ou grafológica do léxico e da gramática até estudos centrados na instanciação do discurso e da ideologia pelo registro e pelo gênero.

Cada círculo concêntrico recontextualiza os círculos menores e assim subseqüentemente (cf.: Martin 1992:496), à medida que a análise passa a enfocar unidades cada vez maiores, da fonologia ao discurso. A linha mais espessa demarca o contexto que circunscreve os planos da fonologia, da gramática e da semântica.

Nessa representação, gênero é uma conformação de significados recorrentes, organizada em estágios e orientada para o objetivo de realizar práticas sociais (cf.: Martin 2002: 269). Essa conformação é específica da cultura (cf.: Halliday 1978: 145), portanto é uma unidade mais ampla do que o texto - "linguagem que é funcional", que realiza uma tarefa em algum contexto (Halliday 1985/1989: 5), "uma instância real de linguagem em uso" (Fairclough 2003:3) - e menos abrangente do que discurso - visões particulares formuladas na linguagem em uso (cf.: Fairclough 2003: 3).

A ampliação do foco dos estudos de gênero da léxico-gramática para o discurso indica a busca por um entendimento mais rico da conexão entre texto e contexto.

6. Atualmente o modelo adotado por Martin (Martin \& Rose, 2003:4) mostra apenas três níveis: o círculo mais interno da gramática, o círculo mais externo da atividade social e o círculo intermediário do discurso, que interfaceia com as duas nomeadas acima. 


\section{A análise da linguagem como gênero sob uma perspectiva crítica}

\subsection{A influência da análise sociológica da linguagem}

De modo geral, na atual terceira fase dos estudos do discurso escrito, o conceito de gênero assume centralidade e é enriquecido por conceitos da perspectiva sociológica ou sócio-histórica de Mikhail Bakhtin (1929/1995), tais como: 1) a heterogeneidade (a instabilidade e fluidez dos usos da linguagem); 2) o dialogismo (a interação entre leitor e autor no espaço do texto); 3) a polifonia (a capacidade do texto de evocar diferentes pontos de vista ou vozes sociais que polemizam entre si, se complementam ou respondem umas às outras), e 4) a intertextualidade (a capacidade de um texto evocar outros textos existentes na cultura) (cf.: Pessoa de Barros 1994: 2-5).

Nos anos 2000, o impacto do pensamento sociológico de Bakhtin e de visões contemporâneas alinhadas com ela, como a Análise do Discurso Crítica de Norman Fairclough, se faz sentir em vários recantos dos estudos da linguagem. No caso da Análise de Gênero, Bakhtin e Fairclough, antes ausentes, aparecem nos livros mais recentes de Swales (1990; 2004) e Bhatia $(1993 ; 2004)$. Também se intensifica a referência a Bakhtin e Fairclough nas obras mais recentes de lingüistas sistêmico-funcionais, como Martin \& Rose (2003).

Mas se o pensamento sociológico ou sócio-histórico representado por Fairclough vem se sedimentando nas discussões sobre gêneros textuais ou discursivos, o emprego da palavra "gênero" por Fairclough também tem se tornado cada vez mais freqüente. Usado como uma ferramenta de teorização e explanação, "gênero" aparece num número crescente de páginas no índice remissivo das obras de fairclough ao longo dos anos. No início da década de 90, em Discourse and social change (Fairclough 1992b), a palavra gênero aparecia em apenas 21 páginas. Uma década mais tarde, em Analysing discourse: textual analysis for social research (Fairclough 2003), a referência a gênero aparece em 94 páginas.

O trabalho de Fairclough (1989: 25) caracteriza-se pelo modelo em três dimensões que adota para a Análise do Discurso Crítica, incluindo o texto, a interação (processos de produção e interpretação do texto) e o contexto mais amplo da sociedade (condições sociais de produção e interpretação do texto). 


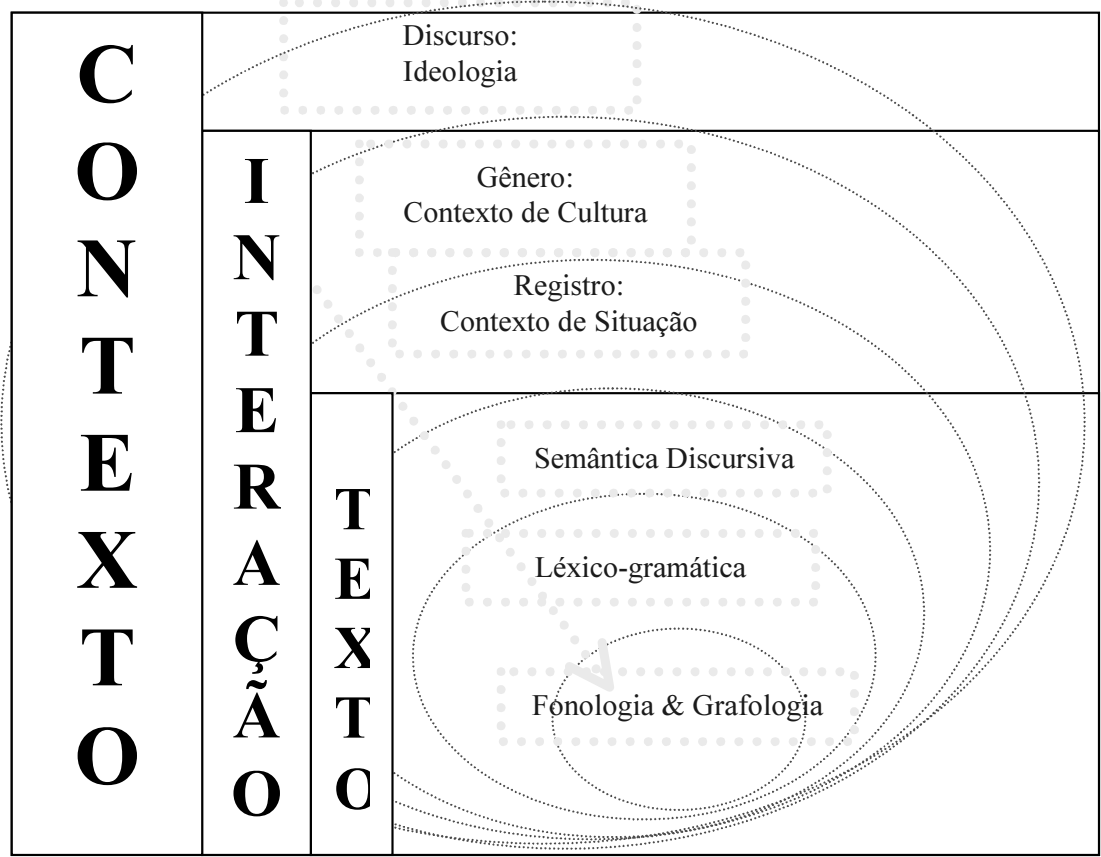

Figura 2: Adaptação da Figura 2.1 - Discurso como texto, interação e contexto de Fairclough (1989:25) e da Figura 7.3 - Linguagem em seu ambiente semiótico de Martin (1992: 496).

Na Figura 2, tento demonstrar uma relação possível entre o modelo discursivo proposto por Fairclough (1989: 25) e o modelo em círculos concêntricos adaptado da lingüística sistêmico-funcional já descrito anteriormente na Figura 1. O nível do texto escrito no modelo de Fairclough equivale à grafologia e à léxico-gramática; a interação corresponde ao registro e ao gênero; e o contexto é o plano mais amplo do discurso e da ideologia, sendo que o gênero que constitui a cultura está num nível intermediário entre a situação e o contexto da totalidade da sociedade.

$\mathrm{Na}$ representação da sistêmica, texto e contexto estão em relação metafórica. A linguagem é uma metáfora para a realidade social (desempenha uma metafunção de representar a realidade social) assim como a realidade social é uma metáfora para a linguagem (cf.: Martin 1992: 494). A dimensão semiótica de uma situação de interação se constitui na léxico-gramática do texto, correspondente a um registro de um gênero específico. Esse gênero, por sua vez, estrutura as instituições, conforme a Figura 2. 
Uma aluna de Química ou um aluno de Letras, cada um gera um registro do gênero artigo científico. Em conjunto, essas várias instâncias do gênero artigo organizam a atividade de relatar a pesquisa, central à instituição academia e, assim, contribuem para o discurso da ciência.

\subsection{A ordem teórico-metodológica da análise dos gêneros}

É interessante notar que em seu texto de 1929/1995, Marxismo e Filosofia da Linguagem, Mikhail Bakhtin refere-se a uma ordem teórico-metodológica para o estudo da língua que é inversa ao desenvolvimento histórico das fases, mostradas acima, que vão do texto para o contexto (cf.: Bhatia 2004).

A ordem teórico-metodológica determinada por Bakhtin (1929/1995: 124) inicia-se pela identificação do contexto social, passando pelos gêneros até chegar às formas gramaticais, a saber:

1. A identificação das formas e dos tipos de interação verbal em conexão com as condições concretas em que se realiza;

2. A identificação das distintas enunciações, dos atos de fala isolados (ou dos gêneros discursivos) em ligação estreita com a interação de que fazem parte; e

3. A análise das formas da língua na sua interpretação lingüística habitual.

A metodologia sociológica de Bakhtin inicia, assim, pelo contexto e segue em direção ao texto. Segundo Swales (2004: 97), o mesmo direcionamento das estruturas "macro" para "micro" é seguida na Análise de Gênero padrão.

Como se pode ver, as abordagens diferenciam-se quanto ao que escolhem analisar em cada nível da planificação da linguagem (Figura 1) e em que ordem fazer isso, se "primeiro o texto" ou "primeiro o contexto" (Askehave \& Swales 2001).

Alguns estudos visam examinar "primeiro o texto", sem uma preocupação com observação direta do contexto, como o tipo de Análise de Gênero estritamente textual, representada nos Exemplos 1 e $2 .^{7}$

7. Ver lista de referências dos exemplos no anexo. 


\section{Data and method}

The introductions and abstracts from these two disciplines were analyzed using the models employed in previous research, namely, Swales (1990) for article introductions and Bhatia (1993) for abstracts.

Exemplo 1 (Samraj 2005:145)

Metaphor identification and classification

The first step concerned identifying the metaphorical expressions in the corpus, and classifying them into the metaphor types recognized in the literature. Expressions were tagged as metaphorical when they illustrated any domain incongruity in reference or attribution.

Exemplo 2 (Caballero 2003:149)

Os Exemplos 1 e 2 caracterizam estudos de gênero que se concentram primeiramente na análise dos elementos lingüísticos em si e incluem alguns comentários ilustrativos das culturas que produziram os textos. As autoras identificam o procedimento de análise pelo nome do pesquisador que o desenvolveu, assumindo que é um procedimento padrão que servirá a qualquer texto. Além disso, olham para o texto, em busca de "similaridades e diferenças entre (...) tipos de texto" (abstracts e introduções de artigos no Exemplo 1), com vistas à análise dos aspectos lingüísticos e textuais (da metáfora, no Exemplo 2), sem se preocupar com a observação inicial e direta do contexto. Esses estudos parecem se identificar com a segunda fase dos estudos de gêneros escritos, que enfocam a macroestrutura dos textos.

Outros estudos buscam "primeiro o contexto", como a Textografia de Swales (1998) (Exemplo 3) ou a Análise Crítica de Gênero (Exemplo 4), que combina a Análise do Discurso Crítica com Análise de Gênero. 
In my own case, if the primary intent of re-exploring the concept of discourse community was clear enough, the types of verbal evidence...were somewhat less clear. What should my occasional research assistants and I be looking at? (...) Because my linguistics specialty is written discourse analysis, an examination of texts would be central. (...) two aspects of the framing context already put to use have been the historical and pictorial. These were originally thought of as providing preliminary contextual background. (...) However, the central and most timeconsuming activity involved the construction of individual textual life histories. The basic procedure (...) was to obtain a curriculum vitae and collect a number of sample publications, study the latter for quite substantial periods of time and from a number of angles, and then conduct one or more major text-based interviews with the chosen author. The resulting transcripts and draft sections then went back and forth with the authors, and (...) outside readers, in the hopes that misunderstandings and obscurities could be ironed out (...)

Exemplo 3 (Swales 1998: 23-24)

O Exemplo 3 ilustra a Textografia de Swales (1998) que inicia, pela observação direta de três comunidades para fazer a reconstituição da história de vida textual de seus membros.

No Exemplo 4, o pesquisador examina o papel das normas e valores socioculturais mais amplos na configuração do gênero, conforme sugerem as perguntas de pesquisa (Al-Ali 2006: 693):

1) Que padrões discursivos típicos do gênero podem ser identificados nos convites de casamento da Jordânia?

2) Como está estruturado o texto do convite? Que interesses são enfatizados por essa formatação textual e interesses são ignorados?

3) Que elementos do contexto sociocultural são relevantes nas cerimônias de casamento e que elementos têm mais influência e poder?

4) Como o conceito de poder (de dominação e autoridade) funciona tecnicamente e como é veiculado no gênero convite de casamento? 
Essas perguntas de pesquisa indicam a preocupação com o contexto, mas enfatizam a reciprocidade com o texto, pois os resultados obtidos na análise do contexto vão ajudar na análise do texto e vice-versa.

\section{Data and procedures}

As far as data collection is concerned, a total of 200 written wedding invitations were collected by 45 (...) English specialists taking BA degrees at Jordan University of Science and Technology, Irbid/Jordan. (...) I asked the students, who come from different regions in Jordan, to collect four or five wedding invitations each from within their own local circle of family and friends. (...).

As a Jordanian, the researcher is an active participant in wedding celebrations in the Jordanian community; thus, via observation and participation in various wedding events, $\underline{I}$ have been able to observe the weddings carried out by families, and that has formed a rich background for my understanding of the people, their life, customs and habits. This in turn gave me, as a researcher, the information I desired about the effect of socio-cultural rules and norms in the wedding invitations. When it is a question of understanding the discursive practices characteristic of culture, we are obliged to seek explanations of their socio-cultural norms through the eyes of those who know the people thoroughly or else incorrect judgments and justification will easily occur. (...). For Bhatia (2004: 113-14), in order for anyone to claim sufficient experience in genre analysis, one needs to have some understanding of the context of text-external aspects of the genre in terms of the broader context in which the genre is to be constructed, interpreted and practiced in real-life situations.(...)

Following Ventola (1987), Swales (1990) and Bhatia’s (2004) move structure analysis of texts (...), the wedding invitations were analyzed for their component moves to determine how the inviters accomplished the overall purpose of their wedding invitations as socio-cultural activities. This involved scanning the texts 
to identify text units expressing particular functions. (...) Through recursive passes through the corpus texts, checking all cases, I developed eight functional categories to include all text units in the corpus. To validate my analysis of the component moves the inviters used, I asked a second rater, who worked as a research assistant, to code independently half of the text corpus (...) there was an 85 percent agreement. (...).

The next two sections present a genre analysis of the corpus at hand in terms of the surface level generic cognitive features, complemented with a CDA analysis of implicit socio-cultural norms teasing the ideology in each generic component of the ritualized wedding invitation. Used together, these two approaches are capable of yielding a clear description, interpretation and explanation of discourse.

Exemplo 4 (Al-Ali, 2006:697-698)

No estudo do Exemplo 4, o pesquisador discute os dados lingüísticos contra o pano de fundo da religião muçulmana e o texto do Alcorão, para demonstrar as marcas ideológicas na linguagem. Assim, a estrutura e a léxico-gramática de um gênero tão ritualizado e resumido como o convite de casamento revela o contexto sociocultural jordaniano.

A estrutura e as escolhas lexicais desse convite (Al-Ali, 2006:706) organizam-se a partir da seguinte ordem canônica dos nomes: na parte superior, logo após um trecho do alcorão, aparece o nome das tribos do noivo e da noiva, seguidos dos nomes dos pais ou guardiões do noivo e da noiva, depois o nome do noivo.

Essa ordem revela duas questões sobre a sociedade jordaniana: 1) a religião ocupa o papel mais importante, seguida do poder tribal, dos laços familiares, e 2) as diferenças hierárquicas entre velhos e jovens e entre homens e mulheres são bem demarcadas. 


\begin{tabular}{|c|c|}
\hline Movimentos & Texto do convite de casamento \\
\hline Introdução & $\begin{array}{l}\text { And among His Signs is this, that he created for you } \\
\text { mates from among yourselves, that ye may dwell in } \\
\text { tranquility with them. And he has put love and mercy } \\
\text { between your (hearts): verily in that are signs for those } \\
\text { who reflect. } \\
\text { (Surah Al Rum, verse 21) }\end{array}$ \\
\hline Título & $\begin{array}{c}\text { Weddings of [Name of groom's Tribe] and [Name of } \\
\text { bride's Tribe) }\end{array}$ \\
\hline $\begin{array}{l}\text { Identificação dos } \\
\text { anfitriões }\end{array}$ & {$[\mathrm{X}]$ \& his wife and Doctor $[\mathrm{Y}]$ \& his wife) } \\
\hline $\begin{array}{l}\text { Pedido de } \\
\text { comparecimento } \\
\text { aos convidados }\end{array}$ & $\begin{array}{l}\text { request the honor of your presence at the wedding } \\
\text { ceremony of }\end{array}$ \\
\hline $\begin{array}{l}\text { Identificação do } \\
\text { noivo (e da } \\
\text { noiva) }\end{array}$ & (His son Doctor) \\
\hline $\begin{array}{l}\text { Localização do } \\
\text { local da } \\
\text { cerimônia }\end{array}$ & ---- \\
\hline Conclusão & $\begin{array}{ll}--- \\
-\end{array}$ \\
\hline $\begin{array}{l}\text { Elementos } \\
\text { opcionais }\end{array}$ & ---- \\
\hline
\end{tabular}

Tabela 1: Análise da estrutura de movimentos retóricos de convite de casamento jordaniano (Al-Ali, 2006)

A Tabela 1 apresenta uma análise estrutural dos movimentos retóricos de um convite de casamento jordaniano (Al-Ali, 2006). O nome da tribo no topo, logo abaixo do texto do alcorão, domina hierarquicamente o nome do pai do noivo, que, por sua vez, domina o nome do noivo. Essa organização retórica do gênero sinaliza o alto grau de dependência do indivíduo em relação à família (cultura de parentesco, kinship culture).

Ao contrário da figura masculina do pai que aparece com o nome completo, com todos os títulos, o nome das mães do noivo e da noiva e da própria noiva, muitas vezes, não são nem incluídos, já que são figuras menos importantes. A mulher não é vista como uma entidade independente, pois é sempre identificada em relação a uma figura masculina: filha de, irmã de, esposa de, mãe de, viúva de. Esse gênero revela como a sociedade jordaniana enfatiza a autoridade masculina e apaga o feminismo (cf.: AlAli 2006:707). 
Os exemplos 3 e 4 ilustram a terceira fase dos estudos de gêneros escritos, com sua ênfase na contextualização do discurso, os aspectos externos da construção dos gêneros.

Em matéria de pesquisa, é possível ver que essas duas direções, "primeiro o texto" ou "primeiro o contexto", referem-se à perspectiva e ao objeto de pesquisa.

As análises que consideram primeiramente as estruturas lingüísticas do texto, eventualmente olharão o contexto para interpretar o texto, como a Análise de Gênero estritamente textual. Por outro lado, as análises que consideram primeiramente as condições de produção, distribuição e consumo do texto, o momento histórico, olham o texto para interpretar a prática social da qual o texto faz parte, como a Análise Crítica de Gênero ou a textografia.

\section{Subsídios da Análise Crítica de Gênero para o ensino}

Se a capacidade crítica consiste na "percepção das relações entre o texto e o contexto", conforme escreve Paulo Freire (1992/2000: 11), então abordagens sociológicas da linguagem, como as de Bakhtin e Fairclough, são críticas porque, em princípio, pressupõem um exame do momento histórico e da organização econômica da sociedade para a análise do texto (cf.: Bakhtin, 1929/1995). Também são críticas porque, ao reconhecer a heterogeneidade do discurso (cf.: Bakhtin, 1929/1995; 1992 a; b; Fairclough 2003), problematizam estruturas fixas das práticas de linguagem.

Especialmente Fairclough (1989: 5) contribui para o pensamento crítico, porque tem um objetivo intervencionista e emancipador ao buscar desvelar os elementos do sistema de relações sociais presentes no discurso e tentar avaliar os efeitos desses elementos sobre as relações sociais.

As várias escolas e desenvolvimentos históricos em pesquisa mencionados contribuíram para a exploração do contexto e do texto sob diferentes ângulos e em diferentes níveis. Em relação ao ensino, podem dar contribuições pedagógicas e conceituais para uma abordagem crítica aos gêneros. Mencionarei especificamente os conceitos de sistema e conjunto de gêneros da sócio-retórica, a proposta d'A Roda, do ciclo de leitura e produção textual da escola australiana, e a idéia de Transposição Didática da escola suíça. 


\subsection{Sistema e conjunto de gêneros da sócio-retórica}

A chamada guinada comunicativa da Análise de Gênero, por influência do trabalho de Bakhtin, se caracteriza por um interesse na intertextualidade e interdiscursividade dos gêneros institucionais, isto é, modos característicos de os gêneros serem produzidos e mediados pela relação deles com textos anteriores (cf.: Berkenkotter 2001: 326-27).

Resultados da influência sociológica de Bakhtin nos estudos de gênero, os conceitos de sistema e conjunto de gêneros, descritos por Devitt (1991) e trabalhados por autores como Swales (2004), Bhatia (2004) e Bazerman (2005), trazem uma importante contribuição na pedagogia de Redação Acadêmica.

Tomemos o exemplo do ambiente universitário e a rede ou sistema de gêneros acadêmicos. Para interagir nessa comunidade, o membro neófito deve compreender a totalidade da interação dos eventos comunicativos que existem dentro dela ou ligados a ela: as atividades nos laboratórios de pesquisa, escritórios dos pesquisadores, programas de pós-graduação, as editoras que publicam os livros dos pesquisadores, as livrarias que os vendem, as bibliotecas que os compram, etc.

Os sistemas de gênero instanciam a participação de todas as partes no processo de produção de conhecimento: pesquisadores, colegas, alunos, coordenação, editores, vendedores, bibliotecárias, audiência-alvo, etc. (cf.: Bhatia 2004: 54). Eles evidenciam a importância da interação dos vários textos, como projetos de pesquisa, orientações, palestras, artigos, livros e resenhas, para a constituição e funcionamento de comunidades específicas (cf.: Devitt 1991: 340).

Para alunos de pós-graduação e pesquisadores iniciantes, o conceito de sistema de gêneros (ou de rede para Swales 2004) é ainda mais importante porque ajuda a entender como cada texto realiza sua parte nessa rede, como os textos juntos delimitam as atividades do grupo social, possibilitando uma melhor adequação ao sistema. Também é importante diacronicamente, porque ajuda a perceber o modo como os vários gêneros resultam de textos anteriores e influenciam os textos futuros (cf.: Devitt 1991: 3534). Sistema é a história de todos os eventos discursivos que se caracterizam em gêneros distintos, como ocorrências intertextuais, cada um como um ato em relação aos anteriores e posteriores. 
Assim, o sistema de gêneros existente no meu local de trabalho na UFSM (LABLER - Laboratório de Leitura e Redação), representado na Figura 3, pode ser descrito como um fluxo intertextual contínuo e não-linear entre um projeto de pesquisa, o produto dessa pesquisa (na forma de livro, por exemplo) e a avaliação do mesmo (na forma de uma resenha do livro publicado). Assim, um projeto de pesquisa guarda-chuva é construído com base em outros textos lidos ou escritos anteriormente pelo grupo ou por outros autores. O projeto é então estudado e implementado, alterado, adaptado, e as idéias advindas daí são buriladas em: 1) sessões de orientação, 2) bancas de trabalhos de alunos, 3) palestras, e pode culminar na 4) publicação de um capítulo de livro que, por sua vez, poderá desencadear a 5) publicação de uma resenha crítica do livro, cuja leitura poderá influenciar novos textos, e assim por diante, num fluxo entre atividades institucionais eminentemente discursivas, orientadas para diferentes objetivos.

Gêneros interrelacionados seguem-se uns aos outros em contextos específicos, porque geram as condições necessárias para as ações discursivas se realizarem, portanto cada gênero terá conseqüências para os outros gêneros (e os atos de fala correspondentes) que se seguem no processo de concretização de nossos objetivos (Bazerman 1994: 98).

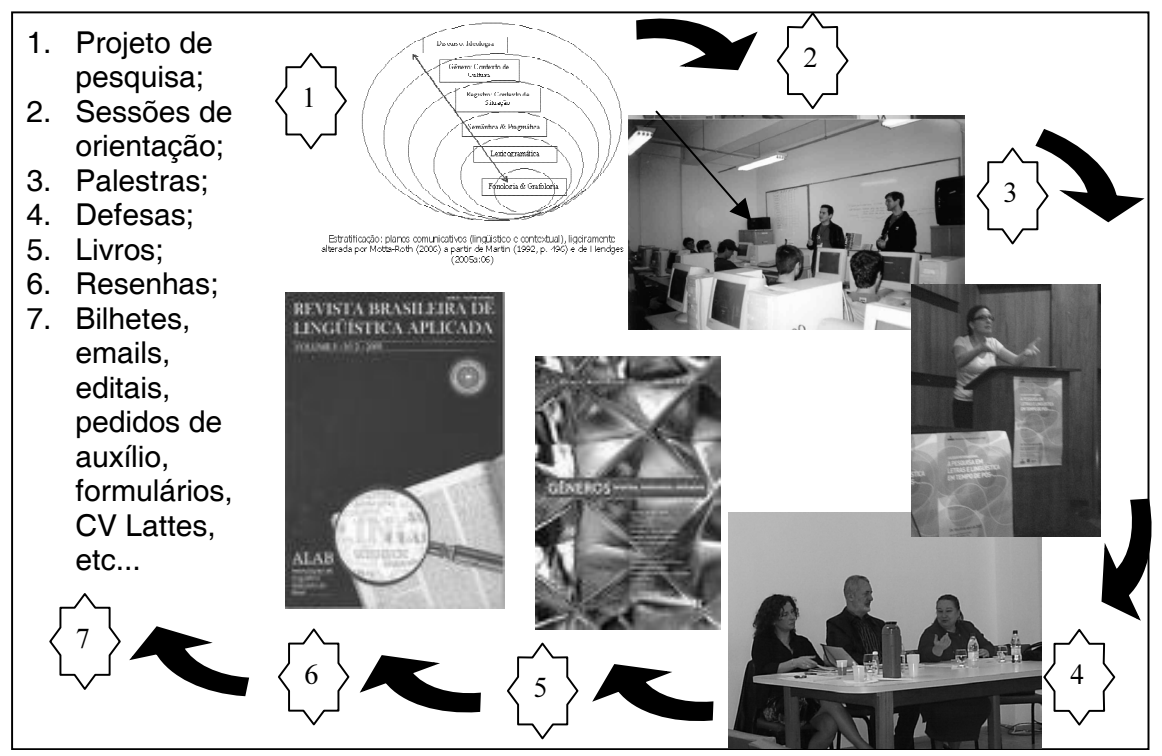


No LABLER/UFSM, esse conjunto compreende gêneros que o grupo produz no decurso de sua rotina diária, como e-mails, pedidos de afastamento, ofícios, o Lattes, os formulários eletrônicos do SIE (Sistema de Informações para o Ensino que armazena e gerencia informações sobre a produtividade acadêmica institucional), etc. Ao longo de um dia, partes ou a totalidade de um abstract, uma resenha, um artigo, projeto de pesquisa, livro, capítulo de livro, volume de anais, etc., são produzidas por um grupo social, cujos membros compartilham interesses comuns.

O conceito de conjunto de gêneros é importante para a compreensão do pesquisador do ambiente de pesquisa universitária e do papel que cada texto desempenha na manutenção da instituição científica. Um aluno de pós-graduação pode se posicionar com mais propriedade na interação acadêmica e produzir textos mais adequados se entender o sistema de interações sociais e a intertextualidade entre os gêneros que estruturam a comunidade em que se inscreve (cf.: Motta-Roth 2001).

\subsection{A Roda - Ciclo de leitura e produção textual da escola australiana}

Outra importante contribuição para a pedagogia de Redação Acadêmica é dada pela proposta de ensino de produção textual com base em gêneros da escola australiana. A proposta d'A Roda (The Wheel) ressalta o ensino explícito da estrutura léxico-gramatical e do modo como se produzem os significados disponibilizados pela linguagem.

O ciclo de Modelagem (leitura exploratória em grupo de exemplares do gênero), Negociação (discussão em aula sobre o gênero e desconstrução dos textos) e Construção textual (produção textual individual), representado em um modelo em forma circular, foi proposto por Jim Martin e colegas da chamada Escola Australiana, dentro do Programa de Pedagogia de Letramento de Gêneros junto a Escolas Carentes, com foco na educação lingüística na escola fundamental (cf.: Cope \& Kalatzis 1993: 11).

Esse ensino é pensado em termos das funções sociais a que a linguagem serve, portanto a linguagem é ensinada como texto que faz parte de um contexto.

Essa abordagem foi acusada de ser voltada para forma e de reforçar uma visão centrada no leitor ao enfatizar a idéia de que o texto deve cor- 
responder às expectativas de uma comunidade acadêmica discursiva ideal. O contra-argumento é que, para o aluno ser capaz de interagir em um contexto social, precisa aprender a socialização naquela comunidade (cf.: Raimes 1991: 412). Sem um conhecimento sistematizado e profundo sobre as tradições retóricas de uma comunidade, neófitos contam com a sorte para aprender com a experiência como participar de um dado gênero (cf.: Devitt 1993: 583).

Cope \& Kalantizis (1993: 8) enfatizam que, apesar de chamar a atenção para a forma da linguagem, essa pedagogia de gênero se diferencia daquelas abordagens formalistas que enfatizam as regras gramaticais como um valor em si mesmas. O projeto da pedagogia de gênero tem caráter político porque visa possibilitar, a grupos historicamente marginalizados pela sociedade letrada e tecnologicamente desenvolvida, o acesso eqüitativo aos gêneros de poder e aos benefícios culturais e sociais decorrentes desse acesso (Kress 1993: 28). Tal acesso demanda o ensino explícito de forma e conteúdo que inclui a análise de exemplares de gêneros pelo grupo de alunos e professor e a produção de textos pelo aluno (cf.: Cope \& Kalantizis 1993: 10-11).

No Brasil, os PCN, as mais recentes OCN, bem como diferente propostas de ensino (cf.: Machado, Lousada \& Abreu-Tardelli 2004a; 2004b; Motta-Roth 2001; 2006a; 2006b), têm demonstrado que as pedagogias voltadas para gêneros discursivos são desejáveis, porque:

apontam caminhos para levar o aluno a se engajar em uma atividade de produção textual como uma forma de estar no mundo, de agir com um objetivo e com um motivo. Algumas sugestões surtirão mais efeito do que outras. (...) O ensino de produção textual com base em gêneros demanda uma descrição detalhada de contextos específicos, a consideração de elementos lingüísticos, que mantêm relação sistemática com o comportamento ou eventos sociais que desejamos explicar (DAVIS, 1995, p. 434). Ao aprender os gêneros que estruturam um grupo social com uma dada cultura, o aluno aprende maneiras de participar nas ações de uma comunidade (MILLER, 1984, p.165). Descobrir como fazer isso consistentemente na sala de aula parece ser o nosso desafio. A sala de aula de línguas talvez seja o lugar onde devemos analisar, criticar e/ou avaliar as várias instâncias de interação humana de culturas localizadas, nas quais a linguagem é usada para mediar práticas sociais. Concordo com McCarthy \& Carter (1994) quando afirmam que ensinar línguas é ensinar alguém a ser um analista do discurso, portanto creio que as discussões em sala de aula devem enfocar as práticas linguageiras nas ações específicas do grupo social relevante (Motta-Roth, 2006a: 510). 
Ações pedagógicas baseadas na noção de gênero no âmbito da planificação também contribuem para a sala de aula. Pesquisadores brasileiros adeptos do ISD têm defendido a construção de "modelos didáticos" de gêneros como forma de intervenção na formação do professor, o que resulta na qualificação do ensino de linguagem (cf.: Machado \& Cristóvão 2006).

\subsection{A proposta de "modelos didáticos" da escola suiça.}

A terceira contribuição para a pedagogia de Redação Acadêmica que enumero neste trabalho vem da idéia referida acima de Modelos Didáticos ou Transposição Didática do ISD (cf.: Machado e Cristóvão 2006). Do mesmo modo que a proposta d'A Roda, o objetivo da construção de Modelos Didáticos de gêneros é promover a análise, a reconstrução e a apropriação de gêneros em atividades pedagógicas comunicativas e prática em contextos culturais específicos. Os Modelos Didáticos servem à aula de redação e de leitura, uma vez que permitem "a visualização das dimensões constitutivas do gênero e a seleção das que podem ser ensinadas" em um determinado nível de ensino (cf.: Machado e Cristóvão 2006: 557).

A construção do Modelo Didático pressupõe a análise de um conjunto de textos considerados como pertencentes ao gênero que se quer estudar/ ensinar, na ordem analítica referida acima no trabalho de Bakhtin, partindo do contexto em direção ao texto. Essa construção de dá com base nos seguintes elementos (cf.: Machado e Cristóvão 2006: 557-8):

a) as características da situação de produção (quem é o produtor (que papel social desempenha), quem é o leitor em potencial (que papel social desempenha), onde e quando o texto é produzido, em que instituição social se produz e circula o gênero, em qual suporte, com qual objetivo, qual o valor social que lhe é atribuído, etc...); b) os conteúdos típicos do gênero;

c) as diferentes formas de mobilizar esses conteúdos;

d) a construção composicional dos conteúdos caracteristicamente associada ao gênero; e) o estilo particular do gênero: as configurações específicas de unidades de linguagem quanto à posição enunciativa do enunciador (presença/ausência de pronomes pessoais de primeira e segunda pessoa, dêiticos, tempos verbais, modalizadores, inserção de vozes); as seqüências textuais (descritiva, explicativa, argumentativa, narrativa, injuntiva, dialogal) e os tipos de discurso (interativo, teórico, relato interativo e narração), predominantes e subordinados que caracterizam o gênero; as características dos mecanismos de coesão nominal e verbal; as características dos mecanismos de conexão; as características dos períodos; as características lexicais. 
A noção de Modelo Didático de gênero e os procedimentos destinados à sua construção parecem cumprir os objetivos para os quais foram elaborados: "subsidiar o ensino de língua materna e o aprendizado do aluno por meio de atividades destinadas ao desenvolvimento das capacidades necessárias para a produção de textos pertencentes a diferentes gêneros" (cf.: Machado e Cristóvão 2006: 559).

Um dos pontos positivos dos Modelos Didáticos propostos pelo ISD é que sua construção não precisa ser teoricamente perfeita e "pura", devendo mobilizar as diversas referências relevantes para o contexto do professor que está propondo o Modelo Didático. Abre-se, assim, a possibilidade da utilização de referências teóricas diversas, de diferentes estudos sobre o gênero a ser ensinado, além de referências obtidas por meio da observação e da análise de práticas sociais que envolvem o gênero, junto a especialistas na sua produção (cf.: Machado e Cristóvão 2006: 557).

É possível perceber quão questionável é a crença de que haja uma grande teoria de gêneros que dê conta da linguagem em toda a sua complexidade, conforme já apontado por Swales (2004: 3). A meu ver, a possibilidade a possibilidade da utilização de referências teóricas diversas de se adotar uma perspectiva mestiça, que mantém uma intertextualidade com autores de várias escolas, é a qualidade mais notável que a perspectiva dos estudos de gêneros tem a oferecer aos estudos da linguagem. Essa qualidade é mais notável especialmente se pensarmos que cada contexto de ensino e pesquisa da linguagem tem um perfil de tempo e espaço particular, portanto tanto o processo de formação de professor quanto o ensino propriamente dito deve ser pensado como uma construção intelectual particular, na qual o professor deve ser preparado para fazer propostas que atendam as necessidades de seu contexto de prática de ensino, em vez de adotar livros didáticos prontos, por exemplo. Nesse sentido, a proposta de pesquisa e ensino de gêneros encoraja o pensamento crítico, conforme argumento a seguir.

\section{Perspectivas para a pesquisa e o ensino}

\section{1. (Re)Colocando a "crítica" na agenda de pesquisa e ensino de gêneros}

No Brasil, a nossa trajetória é particular e global. Por um lado, temos um pensamento fundado no pioneirismo de Paulo Freire, que, no final dos 
anos 50, falava de idéias associadas a "empoderamento" (empowerment) e "conscientização" (awareness) pelo letramento, pensando criticamente sobre educação (cf.: Freire \& Hornton 2003: 100). Muito antes dessas palavras virarem moda nos anos 80 , Freire propunha que a alfabetização de adultos em zonas marginais do estado brasileiro de Pernambuco:

teria de se fundamentar na consciência da realidade da cotidianidade vivida pelos alfabetizandos para jamais reduzir-se num simples conhecer de letras, palavras e frases (Araújo Freire 1996: 35).

Freire chamava a atenção do mundo sobre um raciocínio sobre linguagem, caracterizado pela simplicidade. Para ele, a educação é um ato coletivo e historicizado, caracterizado por princípios de interação.

a) não se pode trazer um material pronto, ahistórico para educar um grupo localizado no tempo e no espaço, pois este necessita de um material associado a sua realidade local, concreta, o lugar imediato onde as pessoas vivem e onde serão alfabetizadas (cf.: Freire \& Horton 2003: 102; Brandão 1986: 24)o ensino e a aprendizagem se estabelecem dialogicamente, portanto a palavra é essencial: "a educação autêntica não se faz de "A" para "B" ou de "A" sobre "B", mas de "A" com "B", mediatizadas pelo mundo', pois alunos e professores "se aprendem juntos”, afinal somente o diálogo, que implica num pensar crítico, é capaz, também, de gerá-lo (cf.: Freire, 1981 98);

b) se aprende a ler, lendo; a prática é importante para o ato de conhecimento (cf.: Freire 2000: 46); o caminho é construído pela caminhada (cf.: Freire \& Horton 2003);

c) se aprende a linguagem na qual se interage, ao se interagir pela linguagem (um princípio adotado pelos autores do Círculo de Estudos de Lev Vygotsky, por quem Paulo Freire foi influenciado (cf.: Freire \& Horton 2003: 62); por ser um processo situado histórica e socialmente, o letramento é crítico e intersubjetivo, portanto se aprende a ler e escrever na sala de aula da escola, desde que esta se constitua em um espaço interativo de aprendizagem;

d) o letramento se dá, usando-se o universo conhecido, os temas e as palavras geradoras, as palavras-chave que caracterizam o dia a dia do aluno (cf.: Brandão 1986: 27; 32-34) como andaimes; é impossível "trabalhar em uma comunidade sem sentir o espírito da cultura que está lá há muitos anos” (Freire \& Horton 2003: 138); por outro lado, ter respeito por essa cultura local não significa que educador não questione, critique ou coloque sobre a mesa a possibilidade de mudança (cf.: Freire \& Horton 2003: 139), nesse sentido a educação é um processo de intervenção (cf.: Freire \& Horton 2003: 143);

e) saber ler a palavra pressupõe saber ler o mundo, ler a realidade social; o pensamento crítico é a capacidade de fazer perguntas sérias aos pontos de vista e às teorias que estão postos (cf.: Freire \& Horton 2003: 228); a leitura crítica é o ato de relaci- 
onar o texto às suas condições socioeconômicas de produção e consumo, implica perceber as relações entre texto e contexto" (Freire 2000: 11) e ao entendimento desse contexto (cf.: Freire \& Hortons 2003: 159).

Se por um lado, nós, pesquisadores brasileiros, contamos com a herança teórico-pedagógica de Paulo Freire, por outro lado, somos leitores atentos do que se passa no planeta, nas várias escolas teóricas que vão se estruturando. Apropriamo-nos desses recursos teóricos e os colocarmos em uso em nossa prática, adaptando-os ao nosso contexto. Assim, realimentamos o ciclo do debate acadêmico. Os PCN e as OCN são exemplos de documentos mestiços porque mantém uma intertextualidade com autores de várias escolas.

A perspectiva crítica defendida por Paulo Freire (e atualmente difundida por tantos outros autores contemporâneos), ao buscar restabelecer as relações entre o texto e suas condições de produção, distribuição e consumo, traz três contribuições principais para a pesquisa da linguagem.

Primeiro, ao propor a análise de elementos lingüísticos e retóricos do texto (como na Análise de Gênero estrita) em combinação com a análise dos elementos ideológicos do contexto (como a Análise do Discurso Crítica), a Análise Crítica de Gênero se presta a uma análise que é, ao mesmo tempo, detalhada, porque explica e localiza os elementos lingüísticos no tempo e no espaço, e problematizadora, porque desnaturaliza os valores que estão postos.

Segundo, ao trazer, para a análise do texto, a preocupação com as práticas sociais, a Análise Crítica de Gênero esclarece o significado dos textos para a vida individual e grupal e o papel estruturador dos gêneros para a cultura:

Utilizando a descrição de Meurer (2004: 137-144) acerca dos princípios da teoria sociológica de Anthony Giddens, podemos dizer que o sistema social se organiza em termos de atividades socialmente reconhecidas (práticas sociais como o atendimento aos clientes de um banco, a aula na universidade, a consulta médica, a entrevista de emprego) e papéis sociais (e as relações de poder entre gerente e cliente, professor e aluno, médico e paciente, empregador e candidato ao emprego), desempenhados pelos participantes de cada atividade. As atividades e os papéis sociais são constituídos por um terceiro elemento, a linguagem (regras e recursos de significação). A linguagem funciona como elemento estruturador dos dois primeiros elementos. Os três se articulam em gêneros - práticas sociais mediadas pela linguagem, comparti- 
lhadas e reconhecidas como integrantes de uma dada cultura. Tal conceito de linguagem, que articula a vida social e o sistema da língua, carrega em si pressupostos acerca do ensino de linguagem: ensinar uma língua é ensinar a agir naquela língua (Motta-Roth 2006a: 496).

Terceiro, ao possibilitar a análise dos valores sociais dos elementos do texto e inscrevê-lo num sistema de atividades, a Análise Crítica de Gêneros permite uma percepção mais acurada da relação entre teoria da linguagem e prática social. Analogamente aos postulados de Vygotsky (1984/2007: 102) sobre a relação entre pensamento abstrato e experiência concreta, entendo que a referência à experiência concreta do sistema de atividades que os textos estruturam é parte necessária da nossa aprendizagem dos gêneros, isto é, do desenvolvimento intersubjetivo de representações abstratas acerca do modo como nos comunicamos, quando, onde e com que formas (mais ou menos estáveis). O envolvimento nas atividades práticas diárias servem de base para a formação social e cultural da mente:

human practice is the basis for human cognition; practice is that process in the course of whose development cognitive problems arise, human perceptions and thoughts originate and develop, and which at the same time contains in itself criiteria of the adequacy and truth of knowledge. Marx says that man must prove truth, activity and power, and universality of his thought through practice. (...) In reality the philosophic discovery of Marx consists not in identifying practice with cognition but in recognizing that cognition does not exist outside the life process that in its very nature is a material, practical process. (Leontiev:12-13).

Duas das questões a serem respondidas pelas futuras pesquisas sobre gêneros discursivos são: 1) De quanto contexto (histórico, social, material, pessoal) precisamos dar conta (cf.: Swales 2004:3) para que possamos ter um nível apropriado de percepção dos exemplares de gêneros? 2) De quanto texto precisamos dar conta, e em que nível de detalhe, para entendermos e participarmos discursivamente do que se passa a nossa volta? Essas são questões centrais que a pesquisa e também o ensino de linguagem de base crítica terão que responder eventualmente.

Há, pelo menos, dois caminhos a serem perseguidos pela investigação e pelo ensino que se subsidiem reciprocamente: estímulo à autoria e valorização do dialogismo e da intertextualidade. 


\subsection{O estímulo à autoria e a valoriz̧ação do dialogismo e da intertextualidade como contribuições teórico-metodológicas para o ensino}

$\mathrm{Na}$ perspectiva crítica, a autoria é trabalhada para que os alunos se transformem em autores de seus próprios textos, de modo a conectar a aprendizagem educacional de seus próprios textos com a interação na vida diária (cf.: Halliday 1991: 13). A constituição da autoria se dá na medida em que as escolhas do objetivo da escritura, o conteúdo e o estilo do texto, bem como do público-alvo se constituem na prerrogativa e responsabilidade de quem escreve (cf.: Ivanic 1998: 26; 219; 341), em relação à cultura do grupo social a quem o texto se destina. Sob uma perspectiva social do sujeito:

The reflection of reality arises and develops in the process of the development of real ties of cognitive people with the human world surrounding them; it is defined by these ties and, in its turn, has an effect on their development. (Leontiev:12-13).

A dinâmica da autoria que identifica a necessidade de escrever e ler e a localiza na vida cotidiana empodera o produtor do texto, constrói uma identidade de autor e projeta um possível leitor.

A valorização do dialogismo e da intertextualidade situa o texto no discurso. A pedagogia de gênero prevê um debate sobre as situações de produção, distribuição e consumo do texto, os textos em si e seus efeitos. Ao propor esse engajamento no diálogo corrente com o mundo e com outros textos, a pedagogia de gênero foge da "pedagogia da exploração temática” (Bunzen 2006:148), na qual o aluno é instado a escrever uma dissertação escolar sobre um tema escolhido pelo professor, sem objetivo específico, sem preocupação sócio-interativa, avaliada essencialmente por seus aspectos normativos e/ou estruturais, lida por uma pretensa audiência - o professor ou o monitor (cf.: Bunzen 2006: 147-8). Para que o aluno possa se inscrever no discurso, a produção textual, por exemplo, deve ser concebida como uma prática social. Para tanto, é necessário que alunos e professores desenvolvam uma visão rica do ato de escrever em si: escrever não pressupõe apenas a produção do texto, mas também seu planejamento (antes), sua revisão e edição (depois) e seu subseqüente consumo pela audiência-alvo, para que autor e leitor possam atingir seus objetivos de trocas simbólicas: 
É importante que alunos e professores conheçam (ou aprendam a conhecer) a situação social dos gêneros relevantes para sua vida nas comunidades-alvo. Para tanto, é fundamental fazer questionamentos tais como: Para que serve esse gênero? Como funciona? Onde se manifesta? Como se organiza? Quem participa e com que papéis (quem pode ou deve escrever e quem pode ou deve ler)? (Motta-Roth 2006a: 505).

O estímulo à autoria e valorização do dialogismo e da intertextualidade são alguns dos elementos que podem apontar caminhos para levar o aluno a se engajar em uma atividade de produção textual como uma forma de estar no mundo, de agir com um objetivo e com um motivo. O papel do professor é possibilitar o desenvolvimento de autores que produzam textos para circulação/publicação onde antes existiam alunos que apenas escreviam textos para serem entregues à professora, para serem lidos por ela com o único fim de serem avaliados (Motta-Roth 2006a: 507).

\section{Observações finais}

É relevante questionarmos se, de fato, o problema a ser atacado pela educação formal é a falta de conhecimento dos alunos sobre as regras da língua padrão. Talvez o problema não seja esse, mas a falta de acesso às atividades de contextos sociais e gêneros hegemônicos. $\mathrm{O}$ aluno conhece a língua materna. Os alunos vivem a vida na língua, namoram, conseguem emprego, escrevem mensagens no celular, escrevem no Orkut, compõem poesia, mas não têm um repertório rico em elementos da língua culta, em gêneros hegemônicos ou atividades associadas a esses gêneros. A pedagogia de gênero oportuniza uma prática de ensino legitimadora "das práticas sociais dos alunos em contextos culturais específicos” (Bunzen 2006:158). Entretanto, em função da alienação econômica e cultural do aluno da escola pública, falta-lhe o engajamento em uma gama mais variada de situações e processos sociais discursivos considerados hegemônicos.

Ensinar linguagem sob a perspectiva de gênero é trabalhar "com a compreensão de seu funcionamento na sociedade e na sua relação com os indivíduos situados naquela cultura e suas instituições”, “com as espécies de textos que uma pessoa num determinado papel [na sociedade] tende a produzir" (Marcuschi 2005: 10-12). 
Também falta à área de ensino de línguas aprofundar o papel da metalinguagem e o metaconhecimento. Não há porque alijar o aluno da discussão sobre o metaconhecimento de linguagem ou sobre as categorias da linguagem. Conforme escreve Halliday (1991:13):

Em aritmética, todo mundo aceitava que a criança tinha que aprender a falar sobre suas habilidades com os números, como adição e subtração; mas se esperava que desenvolvessem habilidades lingüísticas altamente complexas sem usar quaisquer recursos sistemáticos para falar sobre elas. ${ }^{8}$

Do mesmo modo, não vejo como aprender linguagem sem falar dela, usando os termos relativos a esse campo do saber.

Analogamente à descrição de Bakhtin sobre como podemos participar do discurso porque construímos um modelo mental da situação em que nos encontramos com base em toda a nossa vivência em sociedade, Halliday (1985/1989:28) discute a prática social e lingüística em termos de três comportamentos. Ao entrarmos em uma situação, 1) determinamos um campo - o que as pessoas estão fazendo, 2) notamos as relações entre elas e 3) identificamos o modo - aquilo que está sendo realizado por meio da linguagem. Assim, entramos em uma situação com a mente alerta, com certos elementos da linguagem prontos para serem acessados na mente, fazemos previsões quanto à espécie de significados que serão produzidos para que possamos participar da interação naquela situação.

Se aprender linguagem é o mesmo que analisar discurso, então tanto para a pesquisa quanto para o ensino, as representações sobre a situação de ação de linguagem são um ponto de partida para qualquer ação. Essas representações são uma base de orientação para decidir o gênero do texto, "os tipos de discurso, as seqüências, os mecanismos de textualização e os mecanismos enunciativos que comporão o gênero de texto escolhido” (Halliday 1985/1989:92).

Para Halliday (1991:2), o que as pessoas lêem e ouvem, falam e escrevem quando elas estão sofrendo os efeitos de uma determinada ação, quando estão em um determinado contexto de situação? Que objetivo eles espe-

8. No original: "In arithmetic, everyone accepted that the children had to learn to talk about their number skills, like adding and taking away; but they were expected to master highly complex language skills without any systematic resources with which to talk about them." 
ram alcançar por meio da linguagem? E como se sabe que o objetivo foi alcançado?

À Escola, cabe oferecer condições de acesso à explanação e à compreensão do modo como situações de interação social mais e menos institucionalizadas acontecem, se organizam e se desenvolvem, como e por quem os papéis são determinados aos participantes, e os significados disponíveis na língua. Somente ao entender o que acontece, poderemos entender o que está sendo dito ou escrito, pois a situação cria o texto e o texto realiza a situação, materializa-a, viabiliza-a (cf.: Halliday 1991:15).

No campo da pesquisa que visa à descrição e à interpretação das práticas discursivas, a Análise Crítica de Gêneros, ao combinar o quadro teórico da Análise de Gêneros, o da Lingüística Sistêmico-Funcional e o da Análise Crítica do Discurso. Essa combinação oferece um arcabouço teórico rico que permite: a) a descrição dos atos de fala (a ação comunicativa) realizados num texto representativo de um gênero, b) a identificação dos expoentes lingüísticos que realizam esses atos e que fazem referência aos contextos de situação e de cultura que definem o gênero, e c) a interpretação do(s) discurso(s) que permeia(m) o texto e que constituem as relações e tensões sociais num dado evento discursivo.

Em síntese, a pesquisa e o ensino realizados até aqui nos apontam direções, mas resta o desafio de refinar o conceito de contexto relevante para os diversos usos da linguagem (Meurer 2006) de modo que possamos entender, descrever e ensinar os usos da linguagem como práticas situadas e não como sistemas de regras e verdades.

Recebido em outubro de 2007 Aprovado em março de 2008 E-mail: dmroth@terra.com.br

\section{REFERÊNCIAS}

Al-Ali, M. N. 2006. Religious affiliations and masculine power in Jordanian wedding invitation genre. Discourse Society, 17/6: 691-714.

Araújo, A. D. 1998. Gêneros Textuais: Um estudo de resenhas críticas acadêmicas e o ensino de redação. In: A. D. Araújo \& M. S. L.Boakari 
(Orgs.) Integração: linguagem, escola e comunidade. Teresina: Editora da UFPI: 80-93.

. 2004. Gêneros textuais acadêmicos: reflexões sobre metodologias de investigação. Revista de Letras, 26/1-2: p. 21-27. Fortaleza - Ceará. . 2005. Identidade e subjetividade no discurso acadêmico: Explorando práticas discursivas. In: P. L. C. Lima \& A. D. Araújo (Orgs.) Questões de lingüística aplicada: Miscelânia. Fortaleza, CE: Editora da UECE: 11-30.

Araújo Freire, A. M. 1996. A voz da esposa: a trajetória de Paulo Freire. In: M. Gadotti (org.) Paulo Freire: Uma biobibliografia. São Paulo: Cortez/ Instituto Paulo Freire; Brasília, DF: UNESCO: 27-67.

Askehave, I. \& J. M. Swales. 2001. Genre identification and communicative purpose: a problem and a possible solution. Applied Linguistics, 22/2: 195-212.

BakHTin, M. 1952-1953/1992a. Os gêneros do discurso. In . Estética da criação verbal. São Paulo: Martins Fontes: 277-326.

Bakhtin, M. 1952-1953/1992b. O problema do texto. In . Estética da criação verbal. São Paulo: Martins Fontes: 327-358.

Bakhtin, M. (VOLOCHINOV) 1929/1995. Marxismo e filosofia da linguagem. São Paulo: Editora Hucitec.

BAlocco, A. E. 2001. A categoria de gênero em contextos disciplinares: o caso da prosa sobre a literatura. Anais do II Congresso Internacional da ABRALIN. Fortaleza, CE: UFCE/ABRALIN: 1-6.

\& R. Á. DANTAS. 1997. The academic oral presentation as a student genre. Open To Discussion, 7: 25-37. RJ: UERJ.

BALTAR, M. A. R. 2004. Competência discursiva E gêneros textuais: uma experiência com o jornal de sala de aula. Caxias do Sul: EDUCS.

BARBARA, L. \& M. SCOTT. 1999. Homing in on a genre: invitations for bits. In: F. Bargiela-Chiappini \& K. Nickerson (Orgs.). Writing business genres, media and discourses. New York: Pearson Education Limited: 227-254.

BAZERMAN, C. 1988. Shaping written knowledge: the genre and activity of the experimental article in science. Madison, WI: University of Wisconsin Press.

. 1994. Systems of genre and the enactment of social intentions. In: A. Freedman \& P. Medway. Genre and the new rhetoric. London: Taylor \& Francis: 79-101.

2004. What writing does and how it does it: An introduction to analyzing texts and textual practices. Mahwah, NJ/London: Lawrence Erlbaum. 
. 2005. Dionísio, A. P. \& J. C. Hoffnagel (Orgs.) Gêneros textuais, tipificação e interação. São Paulo: Cortez.

Beaugrande, R. A. de \& W. U. Dressler. 1981. Introduction to text linguistics. London: Longman.

Berkenkotter, C. 2001. Genre systems at work: DSM-IV and rhetorical recontextualizatiom in psychotherapy paperwork. Written Communication, 18: 326-49.

BнAтіA, V. 1993. Analysing genre: language use in professional settings. London: Longman.

. 2004. Worlds of written discourse: a genre-based view. London/New York: Continuum.

Biasi-Rodrigues, B. 1999. Organização retórica de resumos de dissertações. Revista do GELNE - Grupo de Estudos Lingüísticos do Nordeste, Fortaleza: 31-37.

2001. O processo de referenciação em gêneros acadêmicos. Anais da $53^{a}$ Reunião Anual da SBPC. Salvador-BA - CDRom.

Bonini, A. 1998. Entrevista por e-mail: pragmática de um gênero (des)conhecido ou problemas comunicativos na variação do gênero. Anais do V Congresso Brasileiro de Lingïística Aplicada. Porto Alegre: UFRGS.

.2002. Gêneros textuais e cognição: Um estudo sobre a organização cognitiva da identidade dos textos. Florianópolis: Insular.

Braga, D. B. 1999. A constituição híbrida da escrita na internet: a linguagem nas salas de bate-papo e na construção de hipertextos. Leitura: Teoria e Prática 34: 23-29. Campinas, SP.

Brandão, C. R. 1986. O que é método Paulo Freire. $11^{\text {a }}$ edição. Coleção Primeiros Passos, vol. 38. São Paulo: Brasiliense.

BRASIL. 1997. SECRETARIA DA EDUCAÇÃO FUNDAMENTAL. Parâmetros Curriculares Nacionais: Introdução aos Parâmetros Curriculares Nacionais. Brasília: Ministério da Educação. Disponível em: http:// mecsrv04.mec.gov.br/sef/estrut2/pcn/pdf/livro01.pdf. Acessado em 21 de fevereiro de 2006.

. 2000. SECRETARIA DA EDUCAÇÃO FUNDAMENTAL. Parâmetros Curriculares Nacionais (ENSINO MÉDIO). Parte I - Bases Legais. Disponível em: http://portal.mec.gov.br/seb/arquivos/pdf/ blegais.pdf. Acessado em 17 de setembro de 2007.

2002. SECRETARIA DE EDUCAÇÃO MÉDIA E TECNOLÓGICA. Linguagens, códigos e suas tecnologias. In PCN + 
Ensino Médio: Orientações Educacionais complementares aos Parâmetros Curriculares Nacionais. Brasília: MEC; SEMTEC. Disponível em http:/ /cenp.edunet.sp.gov.br/Ens_medio/em_pcn.htm. Acessado em 21 de fevereiro de 2006.

. 2004. UNIVERSIDADE FEDERAL DE SANTA MARIA. Projeto Político Pedagógico do Curso de Letras da UFSM. Santa Maria, RS: Departamento de Letras estrangeiras Modernas/ Curso de Letras/ UFSM.

. 2006. SECRETARIA DE EDUCAÇÃO BÁSICA. Orientações curriculares para o ensino médio - Linguagens, códigos e suas tecnologias. Vol. 1. Brasília: Ministério da Educação. Disponível em http:// portal.mec.gov.br/seb/arquivos/pdf/book_volume_01_internet.pdf. Acessado em 29 de julho de 2007.

Bronckart, J.-P. 1999. Atividade de linguagem, textos e discursos: Por um interacionismo sócio-discursivo. São Paulo: EDUC.

Bronckart, J.-P. 2006. Atividade de linguagem, discurso e desenvolvimento bumano. Organização Anna Rachel Machado e Maria de Lourdes Meirelles Matencio. Campinas, SP: Mercado de Letras.

. \& A. R. Machado. 2004. Procedimentos de análise de textos sobre o trabalho educacional. In: A. R. Machado (Org.) O ensino como trabalho: uma abordagem discursiva. Londrina, PR: EDUEL: 131-163.

Bunzen, C. 2006. Da era da composição à era dos gêneros: $O$ ensino de produção de texto no ensino médio. In: C. Bunzen \& M. Mendonça (Orgs.) Português no ensino médio e formação de professor. São Paulo: Parábola:139-61.

Carvalho, G. 2002. Resenhas acadêmicas e sua organização retórica. Revista de Letras, 57:175-194. Curitiba, PR.

Chouliaraki, L. \& N. Fairclough. 1999. Discourse in late modernity: Rethinking critical discourse analysis. Edinburgh: Edinburgh University Press.

Cristovão, V. L. L. 2002. O gênero quarta-capa no ensino de inglês. In: Ângela Paiva Dionísio; Anna Rachel Machado; Maria Auxiliadora Bezerra (Org.). Gêneros Textuais e Ensino. 2a . ed. Rio de Janeiro: Lucerna: 95-106.

Cristovão, V. L. L.; E. L. Nascimento (Orgs.) 2005. Gêneros textuais: teoria e prática II. Palmas e União da Vitória, PR: Kayguangue.

Devitt, A. J. 1991. Intertextuality in tax accounting: generic, referential, and functional. In: C. Bazerman \& J. Paradis (Eds.) Textual dynamics of the professions: historical and contemporary studies of writing in professional communities. Madison, WI: The University of Wisconsin Press: 336-57. 
. 1993. Generalizing about genre: New conceptions of an old concept. College Composition and Communication, 44/4:573-86.

Dionisio, A. P., A. R. Machado \& M. A. Bezerra (Orgs.) 2002. Gêneros textuais $\mathcal{E}$ ensino. Rio de Janeiro: Lucerna.

Dottori Filho, A. \& S. N. Ikeda. 2006. A causalidade: análise de enunciados produzidos em uma reunião imobiliária. Linguagem em (Dis)curso, 6/2:269-97.

Fairclough, N. 1989. Language and power. London: Longman. 1992. Discourse and social change. Cambridge: Polity Press.

.2003. Analysing discourse: textual analysis for social research. London/ New York: Routledge.

Figueiredo, D. C. 1998. Discurso, gênero e identidade: Uma análise crítica de sentenças jurídicas em casos de estupro. Revista Ciências da Saúde, Florianópolis, 17/1:214-232.

Freire, P. 1981. Pedagogia do oprimido. São Paulo: Paz e Terra.

. 2000. A importância do ato de ler-em três artigos que se complementam. $39^{\mathrm{a}}$ ed. São Paulo: Cortez.

. \& M. HORTON. 2003. O caminho se faz caminhando: conversas sobre educação e mudança social. $2^{\mathrm{a}}$ ed. Petrópolis. RJ: Vozes.

FurlanetTo, M. M. 2004. O professor e os gêneros do discurso: o problema do letramento. Anais do $6^{\circ}$ Encontro do Celsul, Florianópolis: UFSC.

Giannoni, D. S. 2002. Worlds of gratitude: a contrastive study of acknowledgement texts in English and Italian research articles. Applied Linguistics, 23/1: 1-31.

Grabe, W. 2002. Conclusion and responses. In: A. Johns (Ed.) Genre in the classroom: multiple perspectives. Mahwah, NJ: Lawrence Erlbaum: 249-267.

Guimarães, A. M. de M. 2005. Reflexões sobre propostas de didatização de gênero. Signum, 8/1:71-88. Londrina.

HallidaY, M. A. K. 1978. Language as social semiotic: the social interpretation of language and meaning. London: Edward Arnold.

. 1985/1989. Part A. In: M. A. K. Halliday \& R. Hasan. Language, context, and text: Aspects of language in a social-semiotic perspective. Oxford: Oxford University Press: 1-49.

. 1991. The notion of "context" in language education. In: T. Lê \& M. McCausland (Eds.) Language Education: Interaction \& Development. Proceedings of the International Conference on Language Education held in Ho Chi Mibn City, Vietnam. Tasmania, Australia: University of Tasmania at Lauceston: 1-26. 
Halliday, M. A. K. \& R. Hasan. 1985/1989. Language, context, and text: Aspects of language in a social-semiotic perspective. Oxford: Oxford University Press.

Heberle, V. M. 1995. Editoriais de revistas femininas sob a perspectiva da análise crítica do discurso. The Especialist, 15/1-2: 137-150. São Paulo: LAEL/PUC-SP.

Hendges, G. R. 2005. A genre and register analysis of electronic research articles from a systemic functional perspective: new medium, new meanings. PHD project. Florianópolis: PPGI/UFSC.

Hyon, S. 1996. Genre in three traditions: Implications for ESL. TESOL Quarterly, 30/4:693-722.

Ivanic, R. 1998. Writing and identity: The discoursal construction of identity in academic writing. Amsterdam Philadelphia: John Benjamins.

Jorge, S. \& V. M. Heberle. 2002. Uma análise crítica do discurso de um folder bancário. In: J. L. Meurer \& D. Motta-Roth (Orgs.) Gêneros textuais e práticas discursivas: Subsídios para o ensino da linguagem. Bauru: EDUSC: 177-198.

KaUfer, D. 2006. Genre variation and minority ethnic identity: exploring the 'personal profile' in Indian American community publications. Discourse E Society, 17/6:761-784.

Kress, G. 1989. Linguistic processes in sociocultural practice. Oxford: Oxford University Press.

. 1993. Genre as social process. In: B. Cope \& M. Kalantzis (Eds.) The powers of literacy. London: Palmer Press: 22-37.

Leontiev, A. N. 1978. Marxism and psychological science. In Activity, consciousness, and personality. Disponível em http://lchc.ucsd.edu/MCA/ Paper/leontev/Leontev1.pdf, consultado em 30/09/2007.

Machado, A. R. 1998. Gêneros e tipos de discurso. Estudos Lingüísticos Anais do XLV Seminários do GEL, 27: 201-205.

. \& V. L. L. CRIstóvão. 2006. A construção de modelos didáticos de gêneros: aportes e questionamentos para o ensino de gêneros. Linguagem em Dis(curso), 6/Especial: 547-573. Disponível em http:// www3.unisul.br/paginas/ensino/pos/linguagem/0603/0603.pdf. Acesso em 11/08/2007.

; E. Lousada \& L. S. Abreu-Tardelli. 2004a. Resumo. São Paulo: Parábola Editorial.

; E. Lousada \& L. S. Abreu-Tardelli. 2004b. Resenha. São Paulo: Parábola Editorial. 
Marcuschi, L. A. 2002. Gêneros textuais: definição e funcionalidade. In Â. P. Dionísio; A. R. Machado; M. A. Bezerra (Orgs.) Gêneros Textuais E Ensino. Rio de Janeiro: Editora Lucerna: 19-36.

Marcuschi, L. A. 2005. Apresentação. In C. Bazerman. Gêneros textuais, tipificação e interação. Trad. e org. de A. P. Dionísio e J. C. Hoffnagel. São Paulo: Cortez: 9-13.

Martin, J. E. 1985/1989. Factual writing: Exploring and challenging social reality. Oxford: Oxford University Press.

. 1992. English text: system and structure. Philadelphia/Amsterdam: John Benjamins.

. 2002. A universe of meaning - how many practices? In A. Johns (Ed.) Genre in the classroom: multiple perspectives. Mahwah, NJ: Lawrence Erlbaum: 269-278.

. \& D. Rose. 2003. Working with discourse: meaning beyond the clause.London/New York: Continuum.

Meurer, J.L. 1998. Aspects of language in self-help counseling. Florianópolis: Pós-graduação em Inglês/UFSC.

. 2000. O conhecimento de gêneros textuais e a formação do profissional da linguagem. In: M. B. M. Fortkamp \& L. M. B. Tomitch (Orgs.) Aspectos da Lingǘstica Aplicada: estudos em homenagem ao Professor Hilário Inácio Bobn. Florianópolis: Insular: 149-166.

. 2004. Ampliando a noção de contexto na lingüística sistêmicofuncional e na análise crítica do discurso. Linguagem em (Dis)curso, 4/ Especial:133-157. Tubarão.

. 2006. Integrando estudos de gêneros textuais ao contexto da cultura. In A. M. Karwoski; B. Gaydecka \& K. S. Brito. (Orgs.) Gêneros textuais: reflexões e ensino. 2a. ed. revista e aumentada. Rio de Janeiro: Lucerna: 165-185.

Meurer, J. L., A. Bonini \& D. Motta-Roth. (Orgs.) 2005. Gêneros: teorias, métodos e debates. São Paulo: Parábola Editorial.

Miller, C. R. 1984. Genre as social action. Quarterly Journal of Speech, 70: 151-67. MotтA-Roth, D. 1995. A move analysis study of book reviews: Defining an academic written genre. In: Anais do XIII Encontro Nacional de Professores Universitários de Língua Inglesa (ENPULI). Rio de Janeiro: PUCRJ e ABRAPUI: 383-398.

2001. Redação acadêmica: Princípios básicos. Santa Maria: Laboratório de Pesquisa e Ensino de Leitura e Redação/Imprensa Universitária, Universidade Federal de Santa Maria. 
2006. O ensino de produção textual com base em atividades sociais e gêneros textuais. Linguagem em (Dis)curso, 6/Especial: 495-517 Disponível em http://www3.unisul.br/paginas/ensino/pos/linguagem/ 0603/07.htm.

. 2006b. Questões de metodologia em análise de gêneros. In A. M. Karwoski; B. Gaydecka \& K. S. Brito. (Orgs.) Gêneros textuais: reflexões e ensino. 2a. ed. revista e aumentada. Rio de Janeiro: Lucerna: 145163.

. \& V. M. Heberle. 2005. O conceito de "estrutura potencial do gênero" de Ruqayia Hasan. In: J. L. Meurer; A. Bonini; D. MottaRoth (Orgs.) Gêneros: teorias, métodos e debates. $1^{\text {a }}$ ed. São Paulo, SP: Parábola Editorial: 12-28.

. \& G. R. Hendges. 1996. Uma análise de gênero de resumos acadêmicos (abstracts) em economia, lingüística e química. Revista do Centro de Artes e Letras, 18/1-2:53-90. Santa Maria, RS.

., G. R. Hendges; E. C. Amoretti \& M. Kloss. 2000. O tradicional e o novo: análise de artigos acadêmicos eletrônicos. Intercâmbio, 9: 2938. LAEL/PUC-SP.

Oliveira, L. P.; M. C. L. Oliveira \& M. G. D. Pereira. 2005. Práticas comunicativas e variação cultural em reuniões empresariais brasileiras: Percepções e reflexões. In M. C. L. Oliveira; B. Hemais \& B. L. Gunnarsson (Orgs.) Comunicação, cultura e interação em contextos organizacionais. Rio de Janeiro: Papel Virtual Editora: 211-248.

Padilha, S. J. \& Barros-Mendes, A. N. N. 2005. Metodologia de análise de livros didáticos de língua portuguesa: desafios e possibilidades. In: M. da G. Costa Val \& B. Marcuschi (Orgs.) Livros didáticos de língua portuguesa: letramento e cidadania. $1^{\mathrm{a}}$ ed. Belo Horizonte: Autentica.

Pessoa de Barros, D. L. 1994. Dialogismo, polifonia e enunciação. In: D. L. Pessoa de Barros \& J.L. Fiorin (Orgs.) Dialogismo, polifonia e intertextualidade. São Paulo: Editora da Universidade de São Paulo.

Raimes, A. 1991. Out of the woods: Emerging traditions in the teaching of writing. TESOL Quarterly, 25/3: 407-30.

Rodrigues, R. H. 2001. A constituição e o funcionamento do gênero jornalístico artigo: cronotopo e dialogismo. Tese de Doutorado. São Paulo: Programa de Estudos Pós-Graduados em Lingüística Aplicada e Estudos da Linguagem/ Pontifícia Universidade Católica de São Paulo.

. 2003. A constituição e o funcionamento do gênero jornalístico artigo. In: Anais da XI International Bakhtin Conference/Proocedings of the Eleventh International Bakhtin Conference. Curitiba: UFPR: 600-625. 
Rojo, R. H. R. 1997. Enunciação e interação na ZPD: do 'non-sense' à construção dos gêneros de discurso. In: Anais do Encontro sobre Teoria e Pesquisa em Ensino de Ciências: Linguagem, Cultura e Cognição - Reflexões para o Ensino de Ciências. Belo Horizonte, MG/Campinas, SP: FEUFMG/UNICAMP: 95-109.

SiLVA, M. C. 2004. O conceito de gênero e o ensino-aprendizagem da leitura em Língua Estrangeira. In: V. L. L. Cristóvão \& E. L. Nascimento (Orgs.) Gêneros textuais: teoria e prática. 1 ed. Londrina: Moriá: 182-91. Swales, J. M. 1981. Aspects of article introductions. Birmingham, UK: The University of Aston, Language Studies Unit.

. 1990. Genre analysis: English in academic and research settings. Cambridge: Cambridge University Press.

. 1998. Other floors, other voices: a textography of a small university building. Mahwah, NJ: Lawrence Erlbaum.

. 2004. Research genres: exploration and applications. Cambridge: Cambridge University Press.

Vian JR., O. 2003. O ensino de inglês instrumental para negócios, a lingüística sistêmico-funcional e a teoria de gênero/registro. The Especialist, 24/1:1-16. LAEL/PUC-SP.

Vygotsky, L. 1986. Thought and language. Translated by A. Kozulin. Massachusetts: The MIT Press. . 1984/2007. A formação social da mente. São Paulo: Martins Fontes.

\section{ANEXO}

Lista de referências dos exemplos:

Exemplo 1: SAMRAJ, B. 2005. An exploration of a genre set: Research article abstracts and introductions in two disciplines. English for Specific Purposes, 24/2:141-156.

Exemplo 2: CABALLERO, R. 2003. Metaphor and genre: the presence and role of metaphor in the building review. Applied Linguistics, 24/ 2:145-67.

Exemplo 3: SWALES, J. M. 1998. Other floors, other voices: A textography of a small university building. Mahwah, NJ: Lawrence Erlbaum.

Exemplo 4: AL-ALI, M. N. 2006. Religious affiliations and masculine power in Jordanian wedding invitation genre. Discourse Society, 17/6: 691-714. 